OPEN ACCESS

Edited by:

Xintong Ge,

Tianjin Medical University General Hospital, China

Reviewed by: Mingming Shi,

Tianjin Medical University General Hospital, China

Ping Lei,

Tianjin Medical University General Hospital, China

*Correspondence: Jingqiong Hu jingqionghu2006@sina.com

Specialty section:

This article was submitted to Cellular Neuropathology, a section of the journal

Frontiers in Cellular Neuroscience

Received: 09 November 2021 Accepted: 02 December 2021

Published: 07 February 2022

Citation:

Hu J and Wang X (2022)

Alzheimer's Disease: From Pathogenesis to Mesenchymal Stem Cell Therapy - Bridging the Missing

\section{Alzheimer's Disease: From Pathogenesis to Mesenchymal Stem Cell Therapy - Bridging the Missing Link}

\author{
Jingqiong $\mathrm{Hu}^{1 *}$ and Xiaochuan Wang ${ }^{2,3}$ \\ ${ }^{1}$ Stem Cell Center, Department of Cell Therapy, Union Hospital, Tongji Medical College, Huazhong University of Science \\ and Technology, Wuhan, China, ${ }^{2}$ Co-innovation Center of Neuroregeneration, Nantong University, Nantong, China, \\ ${ }^{3}$ Department of Pathophysiology, School of Basic Medicine, Key Laboratory of Education Ministry/Hubei Province of China \\ for Neurological Disorders, Tongji Medical College, Huazhong University of Science and Technology, Wuhan, China
}

Alzheimer's disease (AD) is the most prevalent neurodegenerative disease worldwide. With the increasing trend of population aging, the estimated number of AD continues to climb, causing enormous medical, social and economic burden to the society. Currently, no drug is available to cure the disease or slow down its progression. There is an urgent need to improve our understanding on the pathogenesis of AD and develop novel therapy to combat it. Despite the two well-known pathological hallmarks (extracellular amyloid plaques and intracellular Neurofibrillary Tangles), the exact mechanisms for selective degeneration and loss of neurons and synapses in AD remain to be elucidated. Cumulative studies have shown neuroinflammation plays a central role in pathogenesis of AD. Neuroinflammation is actively involved both in the onset and the subsequent progression of $A D$. Microglia are the central player in $A D$ neuroinflammation. In this review, we first introduced the different theories proposed for the pathogenesis of $A D$, focusing on neuroinflammation, especially on microglia, systemic inflammation, and peripheral and central immune system crosstalk. We explored the possible mechanisms of action of stem cell therapy, which is the only treatment modality so far that has pleiotropic effects and can target multiple mechanisms in AD. Mesenchymal stem cells are currently the most widely used stem cell type in $A D$ clinical trials. We summarized the ongoing major mesenchymal stem cell clinical trials in AD and showed how translational stem cell therapy is bridging the gap between basic science and clinical intervention in this devastating disorder.

Keywords: Alzheimer's disease, pathogenesis (nervous system), chronic inflammatory response, neurodegeneration, mesenchymal stem cells, stem cell therapeutics, neuroinflammation

\section{INTRODUCTION}

Alzheimer's disease (AD) is the most common neurodegenerative disease. It is characterized by progressive cognitive impairment, disorientation, executive dysfunction, and personality and behavior changes. According to recent World Alzheimer's Report, there are currently about 50 million people suffering from dementia in the world. With the increasing trend of population aging, it is estimated that by 2050 , the total number of people with dementia in the world will 
reach 152 million (Patterson, 2018). Alzheimer's disease accounts for more than half of them (Prince et al., 2016).

Alzheimer's disease is characterized by two pathological hallmarks: amyloid plaques $(\mathrm{A} \beta)$ and the neurofibrillary tangles (NFTs). A $\beta$ pathology arises from the improper cleavage of the amyloid precursor protein (APP) resulting in $A \beta$ monomers that aggregate forming oligomeric $\mathrm{A} \beta$ and eventually aggregating into A $\beta$ fibrils and plaques (Selkoe, 1994). NFTs are caused by aggregation of hyperphosphorylated Tau protein. Tau is a microtubule-associated protein that stabilizes microtubules (Alonso et al., 1994, 1996, 1997). In AD, tau protein is phosphorylated at multiple sites resulting in dissociation of microtubules from axon and disruption of intracellular trafficking. Furthermore, hyper -phosphorylated Tau forms NFTs which inhibit overall cellular function and eventually lead to neuronal death (Iqbal et al., 1986, 2010).

For decades, the research and development of $\mathrm{AD}$ drugs has mainly focused on these two pathological changes, but clinical trials of drugs targeting these two pathologies have all failed, despite being successful in pre-clinical animal models. In general, there is currently no drug that can reverse or alter the course of Alzheimer's disease. This discrepancy between pre-clinical animal models and clinical translation suggests there is an urgent need to improve our understanding on the pathogenesis of $\mathrm{AD}$.

In this review, we searched the current literature and provided an up-to-date review on the different theories proposed for the pathogenesis of $\mathrm{AD}$, focusing on neuroinflammation, especially on microglia, astrocytes, Natural Killer cells (NK cells), T cells and chronic systemic inflammation. Stem cell therapy holds great promise for $\mathrm{AD}$ treatment due to their pleiotropic effects of being able to target multiple pathogenic mechanisms in AD. Mesenchymal stem cells are currently the most widely used stem cell type in AD clinical trials. We summarized the ongoing major mesenchymal stem cell clinical trials in $\mathrm{AD}$ and showed how translational stem cell therapy is bridging the gap between basic science and clinical intervention in this devastating disorder.

\section{PATHOGENESIS OF ALZHEIMER'S DISEASE}

Different theories have been proposed for $\mathrm{AD}$ pathogenesis. In the 1990s, the amyloid cascade hypothesis was the dominant theory, which claims amyloid $\beta$ is the causative agent in $\mathrm{AD}$ and initiates all other AD pathogenesis (Hardy and Higgins, 1992). However, there are several lines of evidence which disagree with this hypothesis: (i) heavy amyloid $\beta$ loads have been found in many healthy seniors in postmortem brains (Katzman et al., 1988) without causing any cognitive impairment; (ii) amyloid $\beta$ load is not correlating well with cognitive decline, rather, Tau levels are more relevant (Karran and De Strooper, 2016); (iii) anti-A $\beta$ treatment is ineffective in clinical trials despite clear decrease in patients' amyloid $\beta$ load. Later, pathologic Tau theory began to get more popularity. Indeed, hyperphosphorylated Tau proteins are better correlated with cognitive decline. And accumulating data show Tau pathology appears about a decade before amyloid $\beta$ plaques formation (Arnsten et al., 2021).
However, anti-Tau treatment is equally ineffective in clinical trials. In 1987, a seminal study by McGeer et al. (1987) and McGeer and Rogers (1992) aroused researcher's interest in neuroinflammation. They reported activated microglia in the vicinity of amyloid plaques. To further support their finding, large cohort studies showed the incidence among people using NSAIDs chronically for RA (rheumatoid arthritis) deceased significantly in comparison to normal people (Chang et al., 2016). After that, numerous studies have been focused on inflammation in $\mathrm{AD}$, however, all $\mathrm{AD}$ clinical trials using NSAIDs have been proven ineffective so far. Tobin et al. (2019) reported early decrease in neuroblasts of adult neurogenic regions correlates with the extent of cognitive impairment in $\mathrm{AD}$. The impaired neurogenesis occurs prior to amyloid beta accumulation, long before AD clinical manifestation. Since then, there has been a renewed interest in looking at the role of adult hippocampal neurogenesis in the pathogenesis of AD.

Of note, none of the above theories can explain $\mathrm{AD}$ pathogenesis by itself. The pathogenesis of $\mathrm{AD}$ is extremely complicated, various players such as genetic factor, environment factor, neuroinflammation, pathogenic protein propagation, impaired neurogenesis, mitochondrial dysfunction, ROS accumulation, impaired autophagy likely are all involved in this process (as illustrated in Figure 1). Many of these factors interconnect and form a vicious cycle which facilitate the damage in neurons. Neuroinflammation likely plays a central role in the pathogenesis of AD (Sarlus and Heneka, 2017; Kinney et al., 2018; Kaur et al., 2019; Onyango et al., 2021).

\section{Genetic and Environmental Risk Factors}

In general, genetic factors do not account for a large proportion of the pathogenesis of neurodegenerative diseases, except for Huntington's disease (which is entirely inherited). In $\mathrm{AD}$, genetic causes only account for $1-5 \%$ of the total disease (Wingo et al., 2012). AD can be divided into early onset and late onset form depending on the age of disease onset. Early onset Alzheimer's Disease (EOAD) represents less than 10 percent of all patients with Alzheimer's disease. It typically occurs between a person's 30s and mid-60s. The three single gene mutations related to EOAD are Amyloid Precursor Protein (APP) on chromosome 21 (Goate et al., 1991), Presenilin 1 (PSEN1) on chromosome 14 (Sherrington et al., 1995), and Presenilin 2 (PSEN2) on chromosome 1 (Rogaev et al., 1995). Most people with AD have the late-onset form of the disease (LOAD), in which symptoms become apparent in their mid-60s and later. Researchers have not found a specific gene that directly causes late-onset Alzheimer's Disease but a number of risk genes have been identified by large Genome Wide Association Studies (GWAS). APOE $\varepsilon 4$ is the most well-known gene that increases the risk of AD. Studies have shown having one or two $\varepsilon 4$ alleles of the apolipoprotein $\mathrm{E}$ (APOE) gene on chromosome 19 increase a person's risk to two-fourfold (Blacker et al., 1997). Recent studies have identified other genes which increase the risk of developing Alzheimer's disease, including TREM2 (Guerreiro et al., 2012), CD33 (Hollingworth et al., 2011), SORL1 (Scherzer et al., 2004), CLU (Harold et al., 2009), ABCA7 (Hollingworth et al., 2011), 

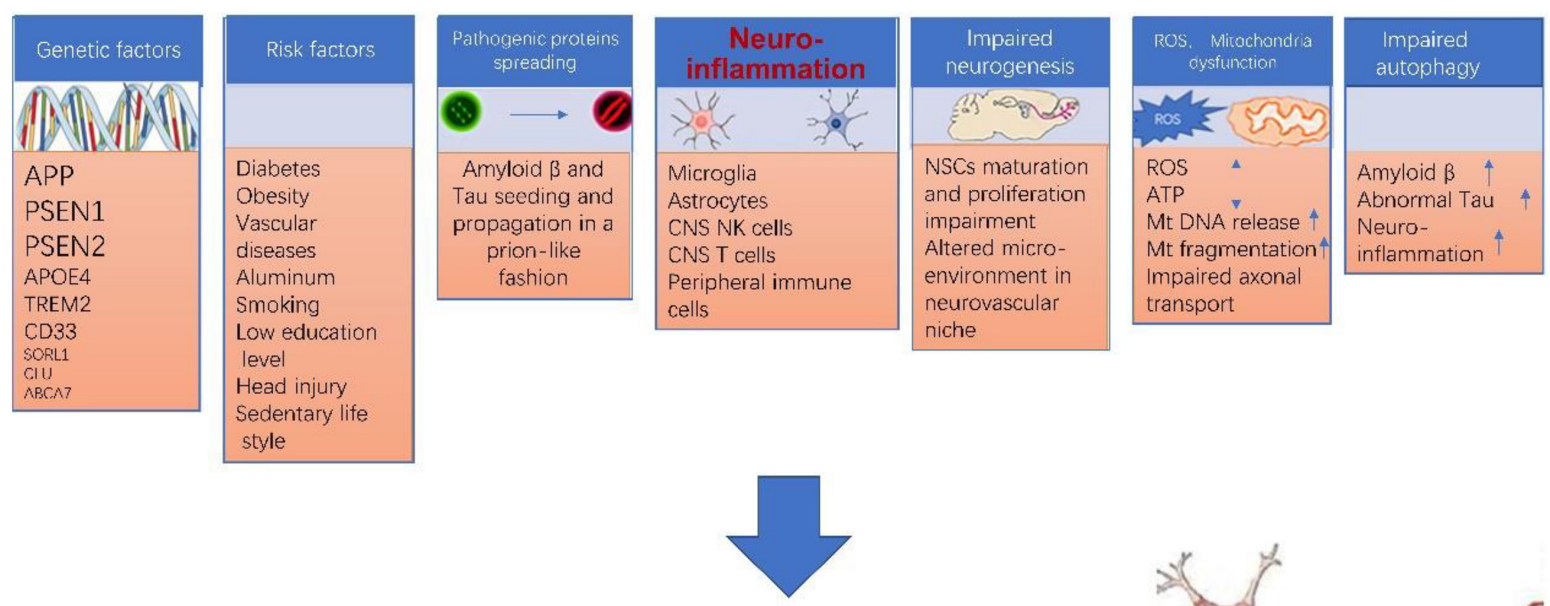

Synaptic loss and neuronal degeneration

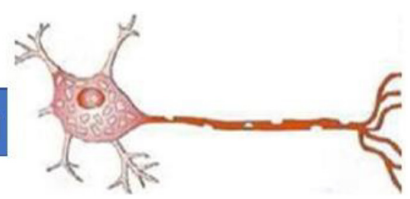

FIGURE 1 | Alzheimer's disease (AD) pathogenesis. The pathogenesis of AD is extremely complicated, various players such as genetic factor, environment factor, neuroinflammation, pathogenic protein propagation, impaired neurogenesis, mitochondrial dysfunction, ROS accumulation, impaired autophagy likely are all involved in this process, and more importantly, many of these factors interconnect and form a vicious cycle which collectively leads to synaptic loss and neuronal degeneration in $A D$.

PINX1 and BIN1 (Harold et al., 2009), etc. TREM2 and CD33 are expressed on microglia of the CNS and play important roles in neuroinflammation, which we will elaborate later. Because genetic form only accounts for a very small percentage of $\mathrm{AD}$, whereas all $\mathrm{AD}$ pre-clinical animal models are based on these three genes, one caveat here is that when we used transgenic mouse models to study the disease, the results are not necessarily extrapolated to human studies. In transgenic mice models, treatments targeting $A \beta$ or Tau protein have a significant improvement effect, but these treatments have all failed in human clinical trials. This suggests the limitations of our transgenic animal model (Korhonen et al., 2018; Kolagar et al., 2020). On the other hand, it also shows that patients are extremely heterogeneous in actual clinical practice, and better animal models are needed to address this heterogeneity.

Other risk factors include head injury (Sullivan et al., 1987), aluminum exposure (Hachinski, 1998), vascular disease (Skoog et al., 1999), smoking (Almeida et al., 2008), midlife hypertension (Ou et al., 2020), hypercholesterolemia (Casserly and Topol, 2004), obesity (Grant, 2004), Diabetes Mellitus (DM) (Arvanitakis et al., 2004), sedentary lifestyle (Xu et al., 2013), psychological stress (Sapolsky et al., 1986), low education attainment (Mortimer et al., 2008), etc.

Of all these risk factors, the importance of vascular diseases has gained increased attention. Some AD patients have clear vascular factors, and thus vascular factors have been considered an $\mathrm{AD}$ comorbidity. In the seminal study published by Snowdon et al. (1997), it was demonstrated that the presence of lacunar infarcts in the basal ganglia, thalamus or deep white matter causes a reduction in the neuropathological threshold (i.e., senile plaque and NFT load) required for any given grading of $\mathrm{AD}$ dementia. After that, accumulating evidences have shown that vascular factors can contribute to $\mathrm{AD}$ pathogenesis in various ways. The pathological changes in vessel hemodynamics, angiogenesis, vascular cell function, blood-brain barrier permeability and immune cell migration can affect parenchymal amyloid deposition, neurotoxicity, glial activation and metabolic dysfunction in multiple cell types (Di Marco et al., 2015).

\section{Impaired Adult Neurogenesis}

In adult mammalian brain, there is ongoing adult neurogenesis, which is the process by which neural stem cells produce new neurons. Adult neurogenesis mainly exists in two specific brain areas, namely the subventricular zone (SVZ) of lateral ventricles and the subgranular zone (SGZ) of the dentate gyrus of the hippocampus (Gage, 2000). A third adult neurogenic region in the ventral hypothalamic parenchyma surrounding the third ventricle has also been reported (Kokoeva et al., 2005). Surprisingly, adult neurogenesis persists until the 9th decade of life in normal aging human brains. In AD patients, impaired neurogenesis began very early (Tobin et al., 2019; Moreno-Jimenez et al., 2021). In minimal cognitive impairment (MCI) phase, the number of PCNA $+\mathrm{Dcx}+$ neuroblasts already decreased drastically, and the decrease further deteriorates as $\mathrm{AD}$ progresses (Tobin et al., 2019). The decrease in neuroblasts correlates with the extent of cognitive impairment. Of note, the impaired neurogenesis occurs prior to amyloid beta accumulation, long before $\mathrm{AD}$ clinical manifestation. Therefore, it is possible that in $\mathrm{AD}$, impairment in neurogenesis, especially in the SGZ neurogenic area, directly affects the learning and memory functions of the hippocampus, and is directly involved in the pathogenesis of $\mathrm{AD}$. 


\section{Autophagy Dysfunction}

Accumulating evidence has shown that autophagy is closely related to stem cell aging and neurodegenerative diseases ( $\mathrm{Li}$ et al., 2017; Kuang et al., 2020). Autophagy is a highly conserved self-repair mechanism in the evolutionary process. Its main function is to degrade longevity proteins in cells and clean up damaged organelles. In $\mathrm{AD}, \mathrm{A} \beta$ and abnormal phosphorylated Tau protein are usually removed by forming autophagosomes and transferring to lysosomes to form autophagic lysosomes. If autophagy dysfunction leads to unsuccessful removal of these pathological proteins, they will accumulate inside the cells and thus affect neuronal function, and at the same time leading to more autophagy dysfunction (Fleming and Rubinsztein, 2020). This theory has received support from genome wide association studies which identifies CLU gene as a risk factor for LOAD (Harold et al., 2009). CLU is a chaperone protein that participates in autophagosome biogenesis. Furthermore, autophagy is closely linked to neuroinflammation. During early stages of $\mathrm{AD}$, autophagy likely plays positive roles to eradicate $A \beta$ and abnormal phosphorylated Tau protein, however, as $\mathrm{AD}$ progresses, autophagy dysfunction will likely exacerbate pathological protein accumulation (François et al., 2014). Targeting autophagy using mTOR might be a new promising strategy to treat AD (Li et al., 2017).

\section{Pathological Protein Accumulation and Prion-Like Propagation-Seed and Soil Theory}

The prion transmission theory of neurodegenerative diseases was initially a controversial theory, but is now widely accepted. This theory states that in each neurodegenerative disease, misfolded protein that adopt an aberrant conformation can provide a template for their own polymerization and thus enable propagation between adjacent cells (Harbi and Harrison, 2014; Walker and Jucker, 2015). As we all know, AD is characterized by presence of hyperphosphorylated Tau and amyloid beta. These pathological proteins, especially amyloid beta, can from prion-like seeds (Prions). These amyloid seeds can continuously replicate, release, and be propagated between adjacent cells in a manner similar to the spread of prion protein lesions. These pathological proteins can also follow the axonal plasm and transported forward or backward to achieve long-distance transmission (Duyckaerts et al., 2019).

\section{Mitochondrial Dysfunction, Excessive Reactive Oxygen Species Damage}

Mitochondria are regarded as the metabolic centers of cells and play pivotal roles in many cell processes, including the immune response. Each mitochondrion contains numerous copies of mitochondrial DNA (mtDNA), a small, circular, and bacterial-like DNA. In response to cellular damage or stress, mtDNA can be released from the mitochondrion and trigger immune and inflammatory responses. Studies have shown excessive ROS and mitochondrial dysfunction are evident in amyloid affected neurons (Tonnies and Trushina, 2017; Singh et al., 2019). Excessive ROS accumulated inside the affected neurons does damage through the following mechanisms: (i) ROS directly do harm to cellular DNA, protein, and membrane (lipid bilayer), destroy their function by causing DNA damage, degradation of cellular protein and lipids; (ii) ROS can induce mitochondrial DNA mutations, damage the mitochondrial respiratory chain, alter membrane permeability, which results in cell energy crisis, mitochondrial transport impairment and mtDNA release; (iii) mtDNA release can further stimulate neuroinflammation (Yoo et al., 2020). ROS damage and mitochondrial dysfunction was once considered the end path in $\mathrm{AD}$, but recent studies have shown excessive ROS is an early event in $\mathrm{AD}$ pathogenesis, and play important roles in early neuroinflammation (Tonnies and Trushina, 2017).

\section{CENTRAL ROLE OF NEUROINFLAMMATION IN ALZHEIMER'S DISEASE}

Neuroinflammation plays a central role in pathogenesis of AD (Heneka et al., 2015; Calsolaro and Edison, 2016; Ahmad et al., 2019; Agrawal and Jha, 2020). According to the classical view, neuroinflammation is characterized by activated microglia and reactive gliosis surrounding the amyloid plaques in $\mathrm{AD}$ (Heneka et al., 2015; Calsolaro and Edison, 2016). In this theory, neuroinflammation is considered a passive reaction toward amyloid plaque and Tau protein. Recent studies suggest neuroinflammation actually precedes AD classical hallmarks, which means neuroinflammation is in itself a contributor to $\mathrm{AD}$ pathogenesis and represents as the third pathological hallmarks of AD (Cuello, 2017). Thus, the neuroinflammation theory has evolved. A recent review by Cuello (2017) best summarizes this new paradigm shift thinking for neuroinflammation in $\mathrm{AD}$. $\mathrm{AD}$ in pathological view needs to be considered as a continuum of disease in which neuroinflammation can be divided into two phases: the early phase and the late phase (Figure 2). The early neuroinflammation phase is the long prodromal phase in $\mathrm{AD}$ (can extends for as long as 1020 years). In this early neuroinflammation phase, a diseaseaggravating CNS inflammation predominates and microglia exhibit a pro-inflammatory profile; In late neuroinflammation phase which represents the phase after $\mathrm{AD}$ clinical manifestation, the neuroinflammation wanes down to great extent.

The importance of underlining this difference is by employing this new paradigm, we move the timeline of neuroinflammation way ahead to $\mathrm{AD}$ prodromal phase. There are several advantages of doing so: first of all, this staging is better in matching Braak pathological stage in AD (Jack et al., 2018; Cummings et al., 2020; Sabbagh, 2020). This also explains why current clinical trials targeting neuroinflammation have all demonstrated lack of efficacy. Most clinical trials recruit only patients with a clear diagnosis of $\mathrm{AD}$, however, even early clinical phase in $\mathrm{AD}$ is already in late inflammation pathological phase. This discrepancy in $\mathrm{AD}$ clinical phase and pathological phase definition most probably accounts for the failure in using NSAIDs in AD clinical trials. The second advantage is that it improves our awareness for inflammation in $\mathrm{AD}$. It is this early inflammation phase which is 


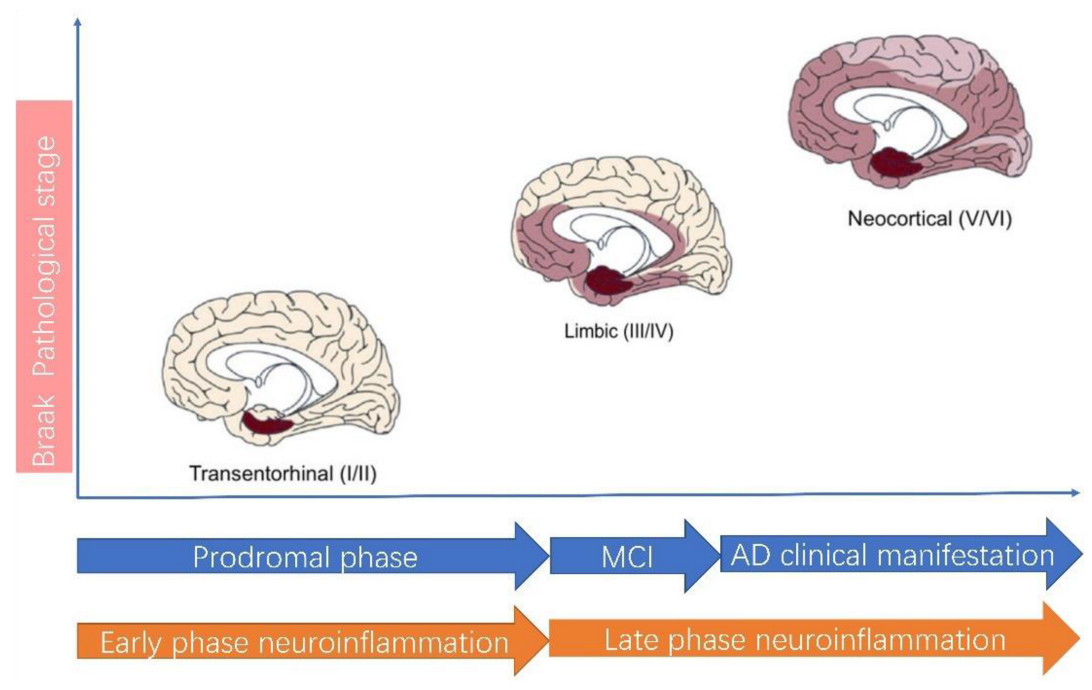

FIGURE 2 | Alzheimer's disease pathological staging versus clinical staging and neuroinflammation staging. According to AD Braak pathological staging (Braak and Braak, 1991), AD can be staged as I-II: Transentorhinal stages, III-IV: limbic stage and V-VI: Neocortical stage. The Transentorhinal stage roughly corresponds to prodromal phase of clinical AD and Early phase neuroinflammation. In Early phase neuroinflammation, microglia assume a detrimental role. The MCI (mild cognitive impairment) stage of clinical AD roughly corresponds to the beginning of Late phase neuroinflammation, during which the neuroinflammation wanes down.

more amenable to anti-inflammation therapy but not the latter (Cuello, 2017).

The central player of neuroinflammation is microglia, however, the importance of astrocytes and other immune cells have gained increased attention in recent years.

\section{Microglia in Alzheimer's Disease}

Microglia are the resident macrophage in central nervous system. Under normal circumstances, resident microglia have a ramified morphology with a small soma, which is described as "resting state" or "quiescent state." Upon stimulation, microglia are activated and attracted to the site and quickly mount an immune reaction and this is helpful to eradicate amyloid and restrict this inflammation to injury site (Heneka et al., 2015; Kinney et al., 2018; Kwon and Koh, 2020). According to the evolved view of neuroinflammation, the first stimulus for microglia in $\mathrm{AD}$ is not amyloid plaques, but rather, amyloid monomers, oligomers or dead neuron debris (Cuello, 2017). After activation, microglia first turned into an antiinflammatory M2 like phenotype by secreting large amounts of IL-10, TGF- $\beta$, IL-4, and IL-13, etc. However, after prolonged activation, they will switch toward a pro-inflammatory M1 like phenotype (Sarlus and Heneka, 2017). The classical M1, M2 classification is actually referring to the peripheral system in which M1 means a pro-inflammatory secreting phenotype for macrophages when they secrete cytokines such as interleukin$1 \beta$ (IL-1 $\beta$ ), tumor necrosis factor- $\alpha$ (TNF- $\alpha$ ), and interleukin6 (IL-6), interleukin-12 (IL-12), etc. M1 is usually associated with decreased phagocytosis activity. M2 means an antiinflammatory phenotype characterized by secretion of large amounts of anti-inflammatory cytokines such as interleukin10 (IL-10), tumor growth factor $\beta$ (TGF- $\beta$ ), and interleukin4 (IL-4), interleukin-13 (IL-13) etc. M2 is usually associated with increased phagocytosis activity. This arbitrary classification of microglia is only partly true when applied to microglia in the CNS because some microglia have been shown to express both M1 and M2 phenotypes (Heneka et al., 2015) and recent studies have identified new types of microglia which don't fit in these M1, M2 definitions (Bisht et al., 2016). Here for simplicity reasons, we still use the M1, M2 term, but adding "like" to the term. The role microglia play in $\mathrm{AD}$ is more like a double- edge sword. During early neuroinflammation phase, activated microglia assume anti-inflammatory M2 like phenotype by secreting large amounts of IL-10, TGF- $\beta$, IL-4, and IL-13, etc. Furthermore, they actively phagocytose amyloid protein, even tau protein. However, prolonged activation of neuroinflammation eventually will stress them out. When they are no longer able to efficiently process large amounts of amyloid load, pathological proteins began to accumulate and aggregate, whereby microglia secret larger amounts of pro-inflammatory cytokines such as IL$1 \beta$, tumor necrosis TNF- $\alpha$, IL-6, and IL-12, etc., similar to M1 phenotype in the periphery (Kwon and Koh, 2020; Onyango et al., 2021). These pro-inflammatory cytokines can direct have impact on APP biosynthesis and lead to further accumulated amyloids and thus form a self-perpetual never-ending vicious cycle, leading to synaptic and neuronal loss in AD. In an APP/PS1 mice AD model, knockout of the NLRP3 inflammasome pathway skews microglia to anti-inflammatory states and protects the mice from memory loss (Heneka et al., 2015).

Microglia also play important role in $\mathrm{AD}$ progression. Studies have shown microglia are primed toward a chronic inflammatory response activation state. This chronic inflammatory response activation state is specifically manifested by the reduction of the excitability threshold of microglia and the long-term sustained secretion of low-level pro-inflammatory factors such as $\mathrm{TNF} \alpha$, IL-6, IL-1, etc. (Sarlus and Heneka, 2017). 
Recent studies have shown microglia in the CNS are heterogenous and may exhibit a variety of phenotypes with distinct functions depending on location, activation state and host environment. For example, a new phenotype of microglia, referred to as "dark microglia," was found in conditions such as chronic stress, including in the APP/PS1 mouse model of AD. Notably, dark microglia exhibited a highly activated phenotype with strong expression of CD11b and TREM2 and extensive encircling of synaptic clefts when the microglia were associated with amyloid deposits (Bisht et al., 2016). Diseaseassociated microglia (DAM) are a subset of microglia showing a unique transcriptional and functional signature (Keren-Shaul et al., 2017; Deczkowska et al., 2018) recently identified by comprehensive single-cell RNA analysis of CNS immune cells in neurodegenerative conditions. These microglia display a dedicated sensory mechanism to detect neural tissue damage in the form of neurodegeneration-associated molecular patterns (NAMPs), a model analogical to the peripheral immune system's pathogen- and damage-associated stress signals (PAMPs and DAMPs) (Chiarini et al., 2020).

\section{Astrocytes}

Astrocytes are the most abundant cell type in the central nervous system. They provide structure, metabolic and neurotrophic support for normal function of neurons. The roles astrocytes played in neuro-inflammation have been increasingly recognized. Astrocyte accumulation in the vicinity of amyloid plaques is among the earliest pathological events in $\mathrm{AD}$ patients and animal models (Heneka et al., 2015). These astrocytes are referred as "reactive astrocytes" and they undergo morphological and transcriptional changes including ramification of hypertrophic processes and increased GFAP (glial fibrillary acidic protein) expression. Astrocytes express multiple genes related to $\mathrm{AD}$, including Apolipoprotein E (APOE), Clusterin (CLU) and Fermitin family member 2 (FERMT2) (Preman et al., 2021). Astrocytes also express enzymes which contribute to the degradation of $\beta$-amyloid. These enzymes include neprilysin (NEP), insulin-degrading enzyme (IDE), and endothelinconverting enzymes 1 and 2 (ECE1 and ECE2) (Preman et al., 2021). Furthermore, astrocytes express aquaporin 4 (AQP4) water channels in their vascular end-feet and play an essential role in the glymphatic system implicated in the clearance of beta-amyloid (Ries and Sastre, 2016). Upon stimulation, they first assume an anti-inflammatory role by secreting of TGF- $\beta$, enhancing phagocytosis of dystrophic neurites and synapses. This phenotype is referred as the A2 phenotype, similar to the anti-inflammatory M2 phenotype of microglia (Ben Haim et al., 2015). However, prolonged activation eventually renders them to exert detrimental effects by producing pro-inflammatory cytokines such as TNF- $\alpha$, IFN- $\gamma$, IL- $1 \beta$, and cyclooxygenase- 2 (COX-2), increased ROS, as observed in several AD mouse model studies (Ben Haim et al., 2015; Heneka et al., 2015). This phenotype is referred as the A1 phenotype. It is generally believed in neuroinflammation, astrocytes and microglia both work in concert. However, microglia likely provide signals to induce astrocytes into reactive phenotype (Liddelow et al., 2017). Despite the common impression of hypertrophy for reactive astrocytes, studies have shown in many parts of the brain in $\mathrm{AD}$, there are atrophic astrocytes (Ben Haim et al., 2015). Atrophic astrocytes are characterized by reduced volume and thinner processes as revealed by morphometric analysis of cells immunolabelled with antibodies against GFAP and S100 $\beta$. In the 3xTg-AD mice model, atrophic astrocytes appear as early as 1-month age in the entorhinal cortex (EC) and the atrophy is sustained after 12 months of age when $\beta$-amyloid plaques begin to appear. Similar to microglia, recent transcriptome study and single cell RNA sequencing technologies also identify heterogeneity within astrocytes population. Furthermore, they likely play dynamic roles in different stages of AD. Recently, Chun et al. (2020) developed an intricate model system which can modulate the degree of astrocytes activation in vivo. Using this system, they showed dysfunctional astrocytes can be divided into mild-moderate reactive astrocytes and severe reactive astrocytes. Mild reactive astrocytes can naturally reverse their reactivity, whereas severe reactive astrocytes have no chance to reverse their reactivity and they can lead directly to tauopathy, neuronal death, brain atrophy, cognitive impairment and eventual death in APP/PS1 AD mice model (Chun et al., 2020). Their finding suggests severe reactive astrocytes can cause neurodegeneration alone, independent of microglia, which adds more complexity to their elusive role in neuroinflammation.

\section{Natural Killer Cells and Activated T Cells}

Normally NK cells and activated $\mathrm{T}$ cells are not seen in central nervous system due to brain-blood barrier (BBB). In the case of acute or chronic brain injury, studies have shown in neurodegenerative diseases such as $\mathrm{AD}, \mathrm{BBB}$ permeability is increased (Ennerfelt and Lukens, 2020). Peripheral immune cells can thus enter the brain through the leaky blood brain barrier, which we will elaborate later. With the advent of single cell sequencing technology, we are beginning to discover more than we previously anticipated. Recent studies have shown, within central nervous system, there are resident NK cells and $\mathrm{T}$ cells in AD patients. Jin et al. (2021) reported recently that NK cells of the innate immune system reside in the dentate gyrus neurogenic niche of aged brains in humans and mice. Neuroblasts within the aged dentate gyrus display a senescenceassociated secretory phenotype and reinforcement of NK cell functions results in $\mathrm{NK}$ cell mediated elimination of aged neuroblasts. These results demonstrate that resident NK cells accumulation in the aging brain impairs neurogenesis, which may serve as a therapeutic target to improve cognition in the aged population. In another study, Zhang Y. et al. (2020) reported that depletion of $\mathrm{NK}$ cells alleviates neuroinflammation, stimulates neurogenesis, and improves cognitive function in a triple-transgenic $\mathrm{AD}$ mouse model. NK cells in the brains of triple-transgenic $\mathrm{AD}$ mouse model (3xTg-AD) mice exhibited an enhanced proinflammatory profile. Depletion of NK cells by anti-NK1.1 Abs drastically improved cognitive function of 3xTg-AD mice. In 3xTg-AD mice depleted of NK cells, microglia demonstrated a homeostatic-like morphology, decreased proliferative response and reduced expression of proinflammatory cytokines. Together, these results suggest a 
proinflammatory role for $\mathrm{NK}$ cells in $\mathrm{AD}$ and depleting of $\mathrm{NK}$ cells can alleviate inflammation and increase cognitive function in $\mathrm{AD}$ mice or patients. Notably, NK cells act not through amyloid $\beta$ but through enhanced neurogenesis and alleviated inflammation.

In another single cell sequencing study, analysis of 14,685 single cell transcriptomes in aged mice brain reveals a decrease in activated NSCs, changes in endothelial cells and microglia, and infiltration of CD8+ T cells in SVZ neurogenic niches (Dulken et al., 2019). Notably, these T cells are clonally expanded which suggest that they have come across some specific antigen in the brain, and not just infiltrate from compromised BBB. These $\mathrm{T}$ cells express interferon $\gamma$, and the subset of NSCs with a high interferon response shows decreased proliferation in vivo. Single cell sequencing technology opens new avenue for our understanding of immune system in the brain. The brain used to be considered an immune-privileged organ, however, this concept has changed and now we know in neurodegenerative diseases such as AD, not only does brain's innate immune system play a role, but also its adaptive immune system.

\section{Peripheral Immune Reaction}

The neuroinflammation in $\mathrm{AD}$ has long been considered a local immune reaction restricted to the CNS, the role that peripheral immune reaction played in this process has been less investigated. However, a growing body of evidence suggests peripheral immune cells play a vital part in the pathogenesis of $\mathrm{AD}$, as illustrated in Figure 3. In neurodegenerative diseases, $\mathrm{BBB}$ is compromised and thus enabling crosstalk between peripheral and central nervous system (Rosenberg, 2012). In AD patients and transgenic animal models, altered levels of proinflammatory cytokines in blood have been frequently reported (Bettcher et al., 2018; Meyer et al., 2018). Recently, Xu and Jia (2021) reported a single-cell transcriptome study from AD patients. They profiled 36,849 peripheral blood mononuclear cells from AD patients with amyloid-positive status and normal controls with amyloid-negative status. They could identify five immune cell subsets: CD4+ $\mathrm{T}$ cells, CD8 $+\mathrm{T}$ cells, $\mathrm{B}$ cells, natural killer cells, and monocytes-macrophages cells. They also found high-frequency amplification clonotypes in $\mathrm{T}$ and $\mathrm{B}$ cells and decreased diversity in $\mathrm{T}$ cells in $\mathrm{AD}$. These findings suggest that the peripheral adaptive immune response, especially mediated by $\mathrm{T}$ cells, may have a role in the pathogenesis of AD.

Peripheral immune cells contribute to $\mathrm{AD}$ pathogenesis via several mechanisms: (i) peripheral immune cells such as $\mathrm{T}$ cells and $\mathrm{B}$ cells, NK cells can enter the brain via BBB, thereby aggregating existing local immune reaction mediated by microglia; (ii) the pro-inflammatory cytokines secreted by peripheral immune cells can also penetrate the brain via $\mathrm{BBB}$, thus integrating into the cytokine network in CNS. On the other hand, there is evidence of the effect of regional neuroinflammation on peripheral immune processes. This means the peripheral and the central immune system is not a one-way street, but rather constantly exchanging (Bettcher et al., 2021).

This new concept allows us to consider the characteristics of immune status as informative indicators for early detection of the
$\mathrm{AD}$ development and for the modulating of immunotherapeutic approaches in $\mathrm{AD}$.

\section{Systemic Inflammation in Alzheimer's Disease}

Cumulative evidence has shown systemic inflammation plays a role in neurodegenerative diseases (Bettcher et al., 2021). Of these systemic inflammation situation, two kinds of inflammation have gained particular interest in recent years. One is periodontitis and the other is gut microbiota dysbiosis (Teixeira et al., 2017; Megur et al., 2020). Recently, attention has been focused on the relationship between periodontitis and AD. Porphyromonas gingivalis ( $P$. gingivalis) and its toxins have been detected in autopsy brain tissues from patients with $\mathrm{AD}$ (Teixeira et al., 2017) but absent in normal patients. $P$. gingivalis is from a Gram-negative periodontal pathogen, Porphyromonas gingivalis (Pg) and/or its product gingipain is/are translocated to the brain. Ilievski et al. (2018) proved repeated exposure (22 weeks) of wild type C57BL/6 mice to orally administered Pg results in neuroinflammation, neurodegeneration, microgliosis, astrogliosis and formation of intra- and extracellular amyloid plaque and neurofibrillary tangles (NFTs) which are pathognomonic signs of AD (Ilievski et al., 2018). In addition, $\mathrm{Pg}$ /gingipain was detected in the hippocampus of mice in the experimental group by immunohistochemistry, confocal microscopy, and qPCR confirming the translocation of orally applied Pg to the brain. Thus this study is the perfect example for using Koch's postulates to prove a microorganism's contribution to a disease. The only caveat is that according to Koch's postulates, the microorganism has to be cultured directly in affected animals. This study is the first to show neurodegeneration and the formation of extracellular $A \beta 42$ in young adult WT mice after repeated oral application of Pg. The neuropathological features observed in this study strongly suggest that low grade chronic periodontal pathogen infection can result in the development of neuropathology that is consistent with that of $\mathrm{AD}$.

In periodontal disease, systemic inflammation affect $\mathrm{AD}$ via two mechanisms: (i) the periodontal bacteria (especially Gramnegative, LPS containing bacteria in the biofilm of periodontal pockets) can produce proinflammatory cytokines locally and these cytokines enter CNS through defect BBB (Teixeira et al., 2017); (ii) In $\mathrm{AD}$, the microglia are already primed toward a pro-inflammatory phenotype (Heneka et al., 2015). Any further inflammatory trigger can intensify the microglia response and exacerbate existing inflammation. Thus periodontitis is believed to play a role in $\mathrm{AD}$ progression. There are also studies reported periodontitis may even play important role in $\mathrm{AD}$ initiation (Dioguardi et al., 2020).

The intestinal microflora takes part in bi-directional communication between the gut and the brain. Gut microflora may even act as the "second brain." They are able to produce several neurotransmitters and neuromodulators like serotonin, kynurenine, catecholamine, etc. (Carranza-Naval et al., 2021). Bacteria populating the gut microbiota can also produce large amounts of amyloids and lipopolysaccharides. Alterations 


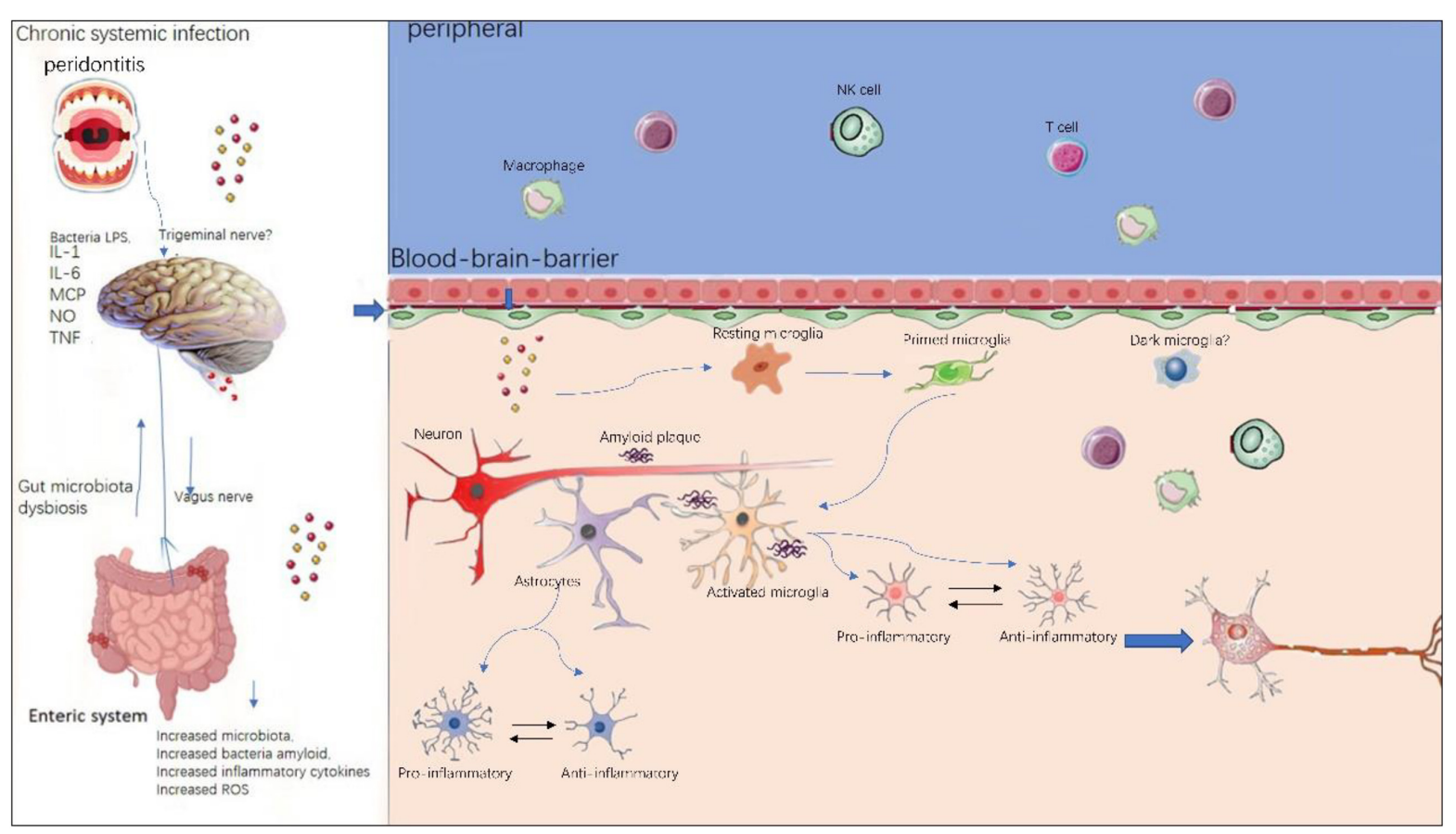

FIGURE 3 | Peripheral and central immune system crosstalk in AD. Chronic systemic infections such as periodontitis and gut microbiota dysbiosis will produce local infection and increased inflammatory cytokines and peripheral immune cells such as peripheral microphages and T cells, NK cells are able to enter the compromised blood-brain-barrier and exacerbate existing neuroinflammation in central nervous system. Within the brain, resident microglia transform from resting state to activated state upon stimulation. Initially, microglia and astrocytes exhibit anti-inflammatory phenotypes, however, sustained chronic inflammation will drive them toward pro- inflammatory phenotypes.

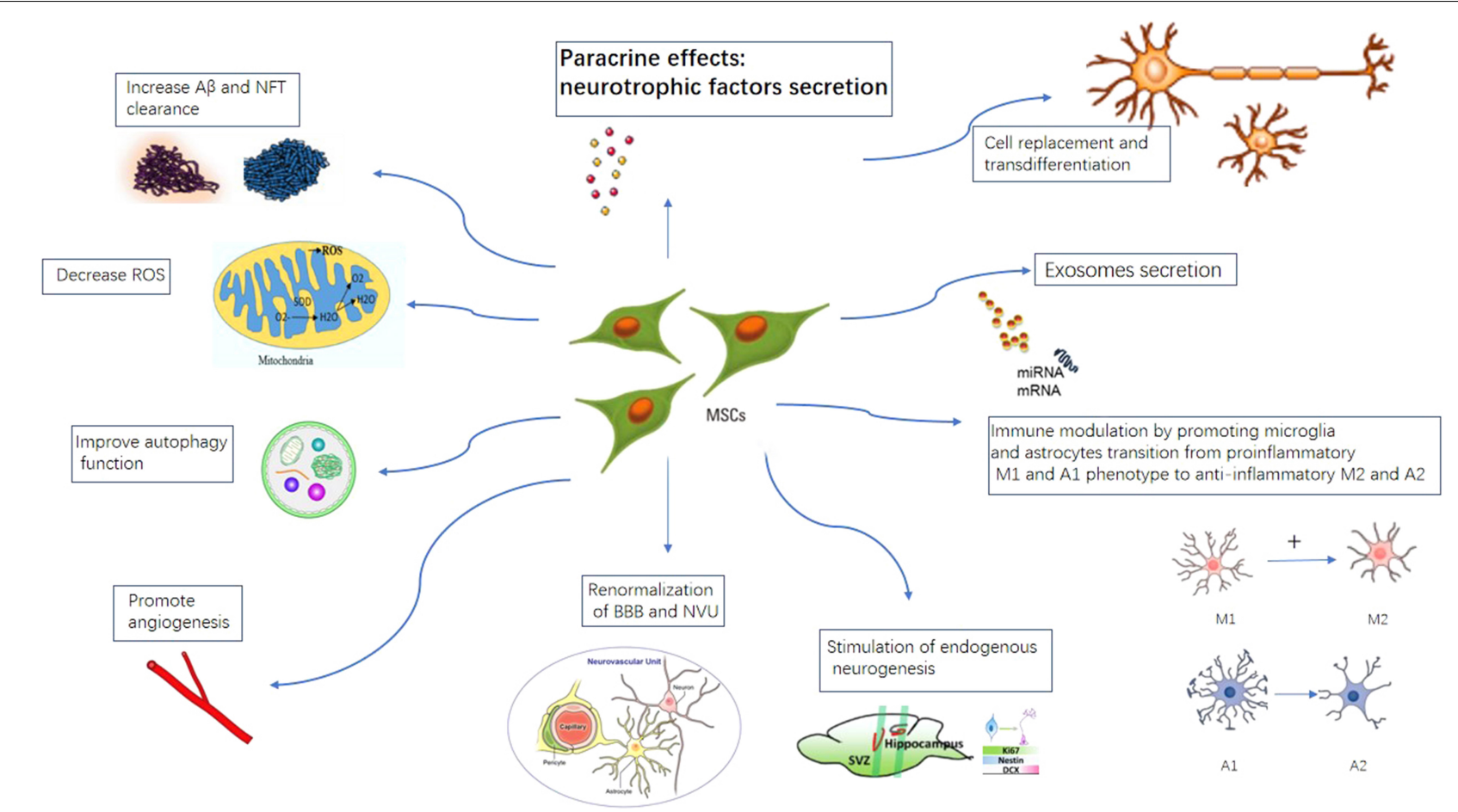

FIGURE 4 | Proposed mechanisms of MSCs therapy in AD. MSCs can take effects by cell replacement, paracrine effects, exosome secretion, immune-modulation, promote angiogenesis, stimulation of endogenous neurogenesis, increase A beta and NFT clearance, improve autophagy, renormalization of blood-brain-barrier. 
in the gut microbiota composition can (i) induce increased permeability of the gut epithelial barrier (Megur et al., 2020); (ii) bacterial amyloids can break the gut barrier into blood stream, finally enter the brain through the leaky blood-brainbarrier (or via olfactory bulb), where they prime residential microglia through molecular mimicry (Friedland, 2015) and promote neuroinflammation, neural injury, and ultimately neurodegeneration. This theory is relatively new and so far only evidence in animal studies. However, it did raise some hope for treating $\mathrm{AD}$ using modulation of gut microbiota such as using probiotics or FMT (Fecal Microbiota Transplantation).

Other studies have shown a connection for HSV infection and AD (Laval and Enquist, 2021). At the same time, a chronic inflammatory state has been shown for $\mathrm{AD}$ and was believed to be directly involved in the progression of $\mathrm{AD}$ (Kwon and Koh, 2020).

\section{MECHANISMS OF NEURONAL AND AXONAL DEGENERATION VIA NEUROINFLAMMATION-A MULTI-STEP PROCESS}

How does amyloid accumulation and neuroinflammation lead to neuronal degeneration and axonal degeneration? The exact mechanism remains to be elucidated. It has been shown in the beginning of $\mathrm{AD}$, amyloid plaques accumulated in various sites of the brain are actually not influencing directly in cognitive function. However, as AD progresses, when synapses are affected and axonal transport is hindered at multiple sites along the axon due to false phosphorylated Tau protein, the neurons will degenerate. Recently, FA Edwards (2019) brought up an elegant hypothesis for amyloid induced neurodegeneration. His hypothesis brings together a wide range of evidence from different laboratories, to address how deposition of amyloid $\beta$, once initiated, eventually leads to Tau tangles and neurodegeneration. He defines the neuronal degeneration in $\mathrm{AD}$ into four steps: (i) accumulation of microglia and astrocytes to amyloid plague; (ii) restriction of neuroinflammation; (iii) synapses are affected along multiple sites of axon; (iv) degeneration of neurons and axons irreversible.

In this hypothesis, he emphasized the important role of microglia. He proposed the efficiency of microglia to eliminate amyloid load determines the progression speed in AD. In healthy seniors, amyloid $\beta$ is frequently detected postmortem. Although amyloid $\beta$ is the trigger for neuroinflammation, studies have shown it is not corresponding to synaptic loss and neuronal neurodegeneration. His proposed theory explains that only when a neuron encounters multiple along its trajectory route, did this become a serious problem. Third, it explains the difference in individuals to AD lies in one's efficiency of microglia to eliminate amyloid load determines the progression speed in $\mathrm{AD}$.

However, this theory doesn't explain the signaling pathways how degeneration of neurons and axons occur. Amyloid signaling pathways include the glycogen synthase kinase-3 $\beta$, nuclear factor kappa B cascade, mitogen-activated protein kinase pathways and c-Jun N-terminal kinase (Chiarini et al., 2020). Amyloid initiate innate immune system through binding to TREM and TLR receptors on microglia. TREM2 is a type- 1 transmembrane glycoprotein predominantly expressed in microglia. TREM2ApoE interaction is essential for the phagocytosis of apoptotic neurons and extracellular debris, from dying or dead neurons. TLRs are a superfamily of pattern recognition receptors and remain the front-line defense against pathogenic infection and tissue injury. TLR- 2 activation triggers $A \beta$-induced inflammation via NF- $\kappa$ B pathway (Gambuzza et al., 2014). TLR-4 have been reported to initiate the inflammatory pathway cascade via mitogen-activated protein kinase (MAPK) and c-Jun N-terminal kinase pathway (Walter et al., 2007; Calvo-Rodriguez et al., 2020). Stimulation of TLRs on microglia can further mount an inflammatory response by the NRLP3 (NACHT, LRR, and PYD domains-containing protein). In an APP/PS1 mice $\mathrm{AD}$ model, knockout of the NLRP3 inflammasome pathway skews microglia to anti-inflammatory states and protects the mice from memory loss (Heneka et al., 2015). As a consequence of the NRLP3 inflammasome activation, caspase- 1 is recruited to the inflammasome, and a number of proinflammatory mediators such as TNF $\alpha$ and IL- $1 \beta$ are released to induce further proinflammatory responses. Hence this neuroinflammatory reaction forms a vicious cycle, triggering further neuronal loss in AD.

Recently, necroptosis, a programed form of necrosis has been proven in postmortem human AD brains (Caccamo et al., 2017; Jayaraman et al., 2021). Unlike apoptosis, necroptosis is executed by the mixed lineage kinase domain-like (MLKL) protein, which is triggered by receptor-interactive protein kinases (RIPK) 1 and 3. Necroptosis was found to be activated in postmortem human AD brains, positively correlated with Braak stage, and inversely correlated with brain weight and cognitive scores (Caccamo et al., 2017). This necroptosis is likely linked to TNF (tumor necrosis factor) -mediated signaling pathway because increased expression of multiple proteins linked to TNF signaling pathway can be predominantly observed in the CA1 pyramidal neurons in the AD post-mortem brain (Jayaraman et al., 2021), accompanied by phosphorylation of RIPK3 and MLKL. These findings suggest targeting TNF-mediated necroptosis might be potential targets in $\mathrm{AD}$ pathogenesis.

\section{FACTORS CONTRIBUTE TO THE SUSTAINED PROGRESSION OF ALZHEIMER'S DISEASE}

Alzheimer's disease has an extremely long latent period (1020 years) before clinical manifestation (Calne et al., 1986). For $\mathrm{AD}$ to be slowly progressive, three factors play important roles: aging status of the host, chronic systemic inflammation and microglia dysfunction.

\section{Aging Status of the Host}

Various studies have shown aging is not only an extremely important risk factor for $\mathrm{AD}$, but also play important roles in the progression of $\mathrm{AD}$. Studies have shown intracerebral injection of beta amyloid is less likely to induce $\mathrm{AD}$ in young mice 
in comparison to old mice (Kane et al., 2000). In aged brain, aging cells feature a decreased ability to proliferate, whereas keep the basic metabolism level and this phenomenon is termed "senescence" (Muñoz-Espín and Serrano, 2014; Kirkland and Tchkonia, 2017). This aging affects neurons, microglia, astrocytes and also neural stem cells in adult neurogenic zones. But most importantly, aging affects our immune system as a whole. Inflammaging and immunosenescence are the two hallmarks of biological aging (Thomas et al., 2020). The term "Inflammaging" was first coined by Franceschi et al. (2007). It refers to the agerelated increase in pro-inflammatory mediators in peripheral blood, which is due to senescence induced secretion of proinflammatory cytokines, causing a state of chronic inflammation without overt infection ("Sterile" inflammation). This means in aged brain, microglia are already primed toward proinflammatory phenotype (Giunta et al., 2008; Heneka et al., 2015; Sarlus and Heneka, 2017).

Aging not only affects the immune system, it also leads to increased oxidative stress (Benz and Yau, 2008). The imbalance between the production of ROS and antioxidants, deteriorates considerably with aging. ROS can directly harm microglia, astrocytes, and neurons (Zuo et al., 2019). ROS can also affect mitochondria function in microglia, astrocytes and neurons. This leads to release of mitochondria cyclic DNA directly to blood stream, exacerbating existing neuroinflammation (Hoye et al., 2008).

In aged brain, there is a decreased endogenous neural stem cell pool. NSCs exhibiting a cellular senescence phenotype have been observed in the dentate gyrus of the APP/PS1 transgenic mouse AD model (Daynac et al., 2014). The neurovascular niche of neural stem cells also shows senescence features in aged brain (Navarro Negredo et al., 2020). Jin et al. (2021) reported elimination of senescent neuroblasts improve cognitive function in transgenic $\mathrm{AD}$ mice model. Inability to replenish adult progenitor cells due to cellular senescence could render the central nervous system susceptible to neurodegeneration.

The blood-brain-barrier is also compromised is aged brain, enabling entry of peripheral immune cells. Vascular cells and specifically endothelial cells and pericytes have been shown to undergo senescence in vitro and in vivo (Tarantini et al., 2017; Huang Z. et al., 2020). Accumulation of senescent endothelial cells is associated with impaired tight junction structure and compromised blood-brain barrier integrity (Yamazaki et al., 2016).

Last but not the least, autophagy is diminished in aged brain (Berglund et al., 2020), further affecting pathological protein eradication.

\section{Chronic Systemic Inflammation}

It's very common for $\mathrm{AD}$ patients to have co-existing chronic systemic inflammation. Importantly, chronic systemic inflammation usually synergizes with inflammaging. For example, in periodontal disease, the periodontal bacteria (especially Gram-negative, LPS containing bacteria in the biofilm of periodontal pockets) can produce proinflammatory cytokines locally and these cytokines enter CNS through defect BBB, where they meet the microglia, which are already primed toward a pro-inflammatory phenotype. This additional inflammatory trigger can intensify the microglia response and exacerbate existing inflammation. Fielder et al., reported using a mouse

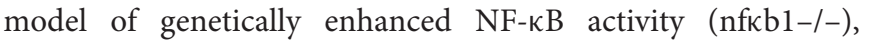
characterized by low-grade chronic inflammation and premature aging, to investigate the impact of chronic inflammation on cognitive decline. They found that during aging, nfkb1-/- mice show an early onset of memory loss, combined with enhanced neuroinflammation and increased frequency of senescent cells in the hippocampus and cerebellum (Fielder et al., 2020). Importantly, treatment with the non-steroidal anti-inflammatory drug (NASID) ibuprofen reduced neuroinflammation and senescent cell burden resulting in significant improvements in cognitive function. These data provide evidence that chronic inflammation is a causal factor in the cognitive decline observed during aging.

Chronic inflammatory state can directly influence cognitive function. Studies have shown AD patients tend to deteriorate more quickly under a chronic inflammatory state (Teixeira et al., 2017).

\section{Microglia Dysfunction}

It has been shown by post-mortem brain autopsy that in many healthy seniors there are as many amyloid plaques as in $\mathrm{AD}$ patients, without causing any cognitive dysfunction (Katzman et al., 1988). To explain this discrepancy, Edwards (2019) has put up an elegant hypothesis. He hypothesized this different outcome is due to the difference in the ability of microglia to eliminate amyloids. In people with normal microglia function who can efficiently remove amyloid plaques, the onset and progression of $\mathrm{AD}$ will be postponed. On the contrary, in people with abnormal microglia function who can't efficiently remove amyloid plaques, a relatively lower plaque load and a relative shorter latency period is sufficient for elicit cognitive decline and eventually AD. But what are the factors contributing the major difference in efficiency of microglia to clear amyloid plaques? Studies have shown this is due to the different expression of TREM2 and CD33 genes on their surface. It has been suggested that the TREM2 is the major positive regulator of microglial phagocytosis whereas CD33 is the key negative regulator of this process (Griciuc et al., 2019). Triggering receptor expressed on myeloid cell 2 (TREM2) is a transmembrane receptor of the immunoglobulin superfamily expressed on the plasma membrane of myeloid cells and microglia, and is active in the innate immune response. TREM2 is a major risk gene identified by genome wide association studies in AD (Gratuze et al., 2018). It can bind to Lipopolysaccharides (LPS), phospholipids, HDL, LDL, APOE, apoptotic neurons, and A $\beta$ (Wolfe et al., 2018), all of which activate signaling pathways. It seems TREM2 is required for microglia to convert from a homeostatic profile to a DAM profile (Ulland and Colonna, 2018). Wang S. Y. et al. (2020), Wang Y. et al. (2020) found that knockout of Trem2 in a $5 x F A D$ mouse model led to exacerbation of $\mathrm{AD}$, with an increased burden of $\mathrm{A} \beta$ plaques in the hippocampus due to a dysfunctional response of microglia, in which they fail to accumulate around $\mathrm{A} \beta$ plaques. 
For $\mathrm{AD}$ to be slowly progressive, the above three factors interact with each other and form a vicious cycle which amplifies the existing neuroinflammation and synaptic and neuronal loss. Aging status is usually accompanied by persisting systemic inflammation; chronic inflammation exacerbates cellular senescence and overall immune status of the patient; dysfunctional microglia further deteriorate chronic inflammation and senescence.

\section{FROM PATHOGENESIS TO THERAPY: MESENCHYMAL STEM CELL THERAPY FOR ALZHEIMER'S DISEASE}

Currently, two types of drugs are commonly used to treat Alzheimer's disease. One is anticholinesterase drugs, including galantamine and Donepezil; the other is excitatory glutamine acid NMDA receptor antagonists, such as Memantine. These drugs are only used for the symptomatic treatment. So far there is no disease-modifying therapies (DMTs) that can halt or reverse the disease process. DMTs clinical trials are arduous. The majority of DMTs clinical trials are aimed at the two classic pathological hallmarks, namely, amyloid and Tau, however, these trials have all failed (Cummings et al., 2020). Recently, the United States FDA adopted an accelerated approval for Biogen's Aduhelm (aducanumab, an amyloid antibody) for the treatment of AD. However, this approach caused a lot of controversy, because in phase 3 clinical trial, its effect is controversy.

The reason for failure in $\mathrm{AD}$ therapy is because the exact mechanisms for selective neuronal loss remains to be elucidated. Current drug clinical trials employ "one drug, one mechanism" concept. AD pathogenesis is extremely complicated and only targeting those single pathological feature such as amyloid beta, Tau, or neuroinflammation is not likely to achieve clinical success. Furthermore, current preclinical animal models are all based on transgenic mice, whereas hereditary form of $\mathrm{AD}$ only represents less than $5 \%$ of the disease. Therefore, direct translation of results in animal models to clinical therapy is not always feasible. Stem cells are a type of cells with selfrenewal and multi-lineage differentiation potential. Stem cells can promote the regeneration and repair of the nervous system, and the core pathological feature of neurodegenerative diseases is the selective loss of neurons, which makes stem cell therapy the ideal treatment option. Stem cell therapy is the only treatment modality which can target multiple mechanisms in $\mathrm{AD}$ and can possibly lead to positive results without knowing the exact mechanisms behind the disease. Ever since the first stem cell therapy attempt using human fetal midbrain tissue to treat Parkinson's disease patient in 1980, four decades have passed. At present, many types of stem cells have been studied in the treatment of $\mathrm{AD}$, including embryonic stem cells (ESCs), neural stem cells (NSCs), mesenchymal stem cells (MSCs), and induced pluripotent stem cells (iPSCs), etc. (Sivandzade and Cucullo, 2021). Mesenchymal stem cells (MSCs) are the most widely used stem cells in AD clinical trials.

Mesenchymal Stem Cells or Mesenchymal Stromal Cells were first discovered by Friedenstein et al. (1974) as adhering cells growing in whirlpool like morphology in the bone marrow. Since then, MSCs have been isolated from various sources such as the adipose tissue, umbilical cord and cord blood, placental tissue, amnion fluid, even the dental pulp (Duncan and Valenzuela, 2017). MSCs can be effectively induced into bone, cartilage, fat, and muscle and even neurons in vitro. Dominici et al. (2006) (i) adhere to plastic surface; (ii) express high levels of CD105, CD73, CD90, and lack expression ( $<2 \%$ positive) of CD45, CD34, CD14 or CD11b, CD79 $\alpha$ or CD19 and HLA class II; (iii) in vitro differentiation into osteocytes, adipocytes and chondrocytes. Nonetheless, MSCs are heterogenous in nature. Studies have shown different subset of MSCs actually have different selfrenewal capacity and also varies in their osteogenic, adipogenic, chondrogenic and neurogenic capacity. These differences are likely attributed to their tissue origins.

Mesenchymal stem cells have many advantages: (i) they aren't involved in any complicated ethical issues as with ESCs and NSCs; (ii) they are easy to obtain, easy to manipulate, easy to stock; (iii) they almost express no HLA antigen and therefore allogeneic transplantation can be achieved without immunosuppression; (iv) they are less prone to tumor formation; (v) MSCs can modulate immune reaction and alleviate neuroinflammation in AD. These amenable features make MSCs currently the most widely used stem cell source in regenerative therapy for $\mathrm{AD}$.

\section{Proposed Mechanisms of Action of Mesenchymal Stem Cells Therapy in Alzheimer's Disease}

Different mechanisms have been proposed for MSCs therapy in AD. The main mechanisms of action of MSCs therapy have long been considered to be "cell replacement." But increasing evidence have shown transplanted MSCs can only survive in the host for a very limited amount of time. Intravenously administered MSCs mostly are trapped in the lung and the spleen (Park B. N. et al., 2018; Kim et al., 2020; Park et al., 2020; Hernandez and Garcia, 2021).

Now it is generally believed transplanted MSCs mainly function through paracrine effects (Walker and Jucker, 2015; Duncan and Valenzuela, 2017; Guo et al., 2020; Kim et al., 2020; Liu et al., 2021). We and others have shown mesenchymal stem cells secrete a large number of neurotrophic and angiogenic factors through paracrine action, especially glial cell derived neurotrophic factor (GDNF), vascular endothelial growth factor (VEGF), brain-derived neurotrophic factor (BDNF), and insulin growth factor (IGF), etc. These neurotrophic and angiogenic factors can potentially improve the microenvironment for the surviving neurons in the diseased area, and promote neuron regeneration and repair. Santamaria et al. (2021) recently reported intranasal administration of secretome collected from MSCs exposed in vitro to $\mathrm{AD}$ mouse brain homogenates (MSCCS) induced persistent memory recovery, with dramatic reduction in amyloid plaque load and reactive gliosis in APP/PS1 $\mathrm{AD}$ mice model. They also found a higher neuronal density in cortex and hippocampus, associated with a reduction in hippocampal shrinkage and a longer lifespan indicating healthier 
conditions of MSC-CS-treated compared to vehicle treated APP/PS1 mice. This suggests the positive effects associated with MSCs transplantation in AD such as improvement on memory, accelerated amyloid plaque clearance, alleviated neuroinflammation and stimulation of endogenous neurogenesis can all be mimicked using MSCs derived secretome, which strongly indicates that the paracrine effects of MSCs play an important role in MSCs transplantation studies.

Another important mechanism for MSCs therapy is modulation of neuroinflammation. As aforementioned, neuroinflammation plays pivotal roles in the pathogenesis of AD. Multiple studies have shown mesenchymal stem cells can convert microglia and astrocytes from pro-inflammatory phenotypes M1 and A1 to anti-inflammatory phenotypes M2 and A2, thereby alleviating the neuroinflammatory response and neuronal damage in AD (Wei et al., 2018; Zhao et al., 2018; Qin et al., 2021). Zhao et al. (2018) recently showed that intracerebral transplantation of menstrual blood- derived MSCs dramatically improved the spatial learning and memory of APP/PS1 mice. The expression of proinflammatory cytokines were remarkably reduced and they suggest the switching of microglia from pro-inflammatory phenotype to anti- inflammatory phenotype likely explains the positive effects. Xie et al. (2016) reported intravenously transplanted Wharton's Jelly MSCs significantly improved the spatial learning and alleviated the memory decline in the APP/PS1 mice. A $\beta$ deposition and soluble $A \beta$ levels were significantly reduced after WJ-MSCs treatment. WJ-MSCs significantly decreased the expressions of pro-inflammatory cytokines IL-1 $\beta$ and TNF $\alpha$ and at the same time, increased the expression of the anti-inflammatory cytokine IL-10. In another study, Ma et al. (2013) transplanted Adipose derived MSCs (Ad-MSCs) intracerebrally into APP/PS1 transgenic mice. Ad-MSCs dramatically reduced $\beta$-amyloid $(A \beta)$ peptide deposition and significantly restored the learning/memory function in these mice. It was observed that in both regions of the hippocampus and the cortex there were more activated microglia, which preferentially surrounded and infiltrated into plaques after ADSC transplantation. The activated microglia exhibited an activated phenotype, as indicated by their decreased expression levels of proinflammatory factors and elevated expression levels of anti-inflammatory factors, as well as $A \beta$-degrading enzymes. These studies suggest MSCs transplantation can alleviate cognitive decline in $\mathrm{AD}$ mice through anti-neuroinflammation mechanisms.

Recent studies have shown early in $\mathrm{AD}$, there is impaired endogenous neurogenesis and decrease neural stem cell pool in adult hippocampus neurogenic regions (Tobin et al., 2019; Moreno-Jimenez et al., 2021). MSCs transplantation can potentially take effect by replenishing the endogenous neural stem cell pool and stimulating neurogenesis. Yan et al. (2014) reported increased neurogenesis in SVZ and SGZ hippocampal regions after adipose tissue derived MSCs transplantation in APP/PS1 mice model.

The MSCs can also directly target classical AD hallmarks. Multiple studies using MSCs transplantation in AD transgenic mice models have shown reduced $A \beta$ plaque burden and decreased levels of tau hyperphosphorylation (Naaldijk et al., 2017; Zhao et al., 2018; Santamaria et al., 2021). Soluble intracellular adhesion molecule-1 (sICAM-1) secreted by umbilical cord derived MSCs can induce the expression of neprilysin (a A $\beta$-degrading enzyme) and thus facilitate $A \beta$ clearance. MSCs can further reduce $A \beta$ plaque burden through internalization and $A \beta$ degradation of endosomal-lysosomal pathway. In animal studies, MSCs transplantation have been shown to improve the symptoms of $\mathrm{AD}$ rats by accelerating the clearance of amyloid and tau (Kim et al., 2012). Zhao et al. (2018) reported Menstrual blood derived MSCs transplantation dramatically reduced tau phosphorylation at Ser202/Thr205 (AT8) and Ser396 sites in the brains of APP/PS1 mice.

Mitochondrial transfer as a new mechanism of stem cell therapy has attracted wide attention and has been considered as a potential therapy for tissue damage. Studies have shown that mesenchymal stem cells may transfer their healthy mitochondria to dying neurons to restore energy metabolism and save neurons (Hayakawa et al., 2016). Mitochondrial transfer can be achieved via extracellular vesicle (EV), TNT (tunneling nanotube) or cell fusion (Wang and Gerdes, 2015; Liu et al., 2019; Gomzikova et al., 2021). Although so far mainly proven in brain ischemia animal models (Huang L. et al., 2020), it might also play a role in AD. Recently, Zhang L. et al. (2020) reported human umbilical cord mesenchymal stem cells (hucMSCs) can donate healthy mitochondria to okadaic acid (OA)-treated SH-SY5Y cells and restore their mitochondria function in an AD cell model (Zhang Z. et al., 2020).

Other mechanisms being implicated for MSCs therapy in AD include enhancing autophagy, decrease ROS (Guo et al., 2021), renormalization of $\mathrm{BBB}$ and $\mathrm{NVU}$ (neural-vascular unit).

Exosomes have drawn much attention in the stem cell therapy field recently. MSCs derived exosomes are enriched in neurogenic and angiogenic cytokines, mRNA and microRNA. These substances can be secreted and transferred to other cells or used to control the surrounding microenvironment. Exosomes can be transferred to target cells through the BBB without being degraded in blood because they are surrounded by lipid bilayer (Chen et al., 2021). Recently, an exosome- based mesenchymal stem cell trial is launched in China. Nasal inhalation of exosomes of allogeneic adipose-derived mesenchymal stem cells is used for the treatment of mild to moderate AD patients (NCT04388982).

Different mechanisms for MSCs therapy in AD are illustrated in Figure 4. At present, there are 17 clinical trial studies of mesenchymal stem cell treatment of Alzheimer's disease registered on the United States clinicaltrial.gov website. A table of current ongoing (and completed studies as well) MSCs clinical trials for AD is listed in Table $\mathbf{1 .}$

\section{Limitations of Current Mesenchymal Stem Cells Trials for Alzheimer's Disease}

Despite the safety being demonstrated in MSCs clinical trials, efficacy has not been proven. We must keep in mind that by the time $\mathrm{AD}$ is clinically diagnosed, the neuronal loss and pathological proteins have already accumulated in many brain regions and therefore it is difficult to reverse the disease process. Furthermore, in many clinical trial protocols, patients may receive only several times of stem cells infusion, whereas they indeed might need multiple stem cells infusions over 
TABLE 1 | Major MSCs clinical trials for AD.

\begin{tabular}{|c|c|c|c|c|c|c|c|c|}
\hline Trial ID & NCT02833792 & NCT04482413 & NCT03117738 & NCT03172117 & NCT02054208 & NCT01297218 & NCT02600130 & NCT04388982 \\
\hline Date & $\begin{array}{c}06 / 2016- \\
06 / 2023\end{array}$ & $\begin{array}{l}12 / 2021- \\
12 / 2023\end{array}$ & 2017/5-2019/8 & $\begin{array}{c}05 / 2017- \\
12 / 2021\end{array}$ & $\begin{array}{c}03 / 2014- \\
12 / 2019\end{array}$ & 02/2011-12/2011 & $\begin{array}{l}\text { 10/2016- } \\
09 / 2021\end{array}$ & $\begin{array}{c}07 / 2020- \\
08 / 2022\end{array}$ \\
\hline Sponsors & $\begin{array}{l}\text { Stemedica Cell } \\
\text { Technologies, } \\
\text { Inc. }\end{array}$ & $\begin{array}{l}\text { Nature Cell Co } \\
\text { Ltd }\end{array}$ & $\begin{array}{c}\text { Nature Cell Co } \\
\text { Ltd }\end{array}$ & $\begin{array}{l}\text { Medipost Co } \\
\text { Ltd. }\end{array}$ & Medipost Co Ltd. & Medipost Co Ltd. & $\begin{array}{l}\text { Longeveron } \\
\text { Inc. }\end{array}$ & $\begin{array}{l}\text { Cellular } \\
\text { Biomedicine } \\
\text { Group Ltd. }\end{array}$ \\
\hline Country & US & US & US & Korea & Korea & Korea & US & China \\
\hline $\begin{array}{l}\text { Study } \\
\text { design }\end{array}$ & $\begin{array}{l}\text { Multi-center, } \\
\text { randomized, } \\
\text { single-blind, } \\
\text { placebo- } \\
\text { controlled, } \\
\text { crossover study }\end{array}$ & $\begin{array}{c}\text { Randomized, } \\
\text { Double-Blind, } \\
\text { Active- } \\
\text { Controlled }\end{array}$ & $\begin{array}{l}\text { Randomized, } \\
\text { Double-Blind, } \\
\text { Placebo- } \\
\text { Controlled }\end{array}$ & $\begin{array}{l}\text { Quadruple } \\
\text { (Participant, } \\
\text { Care Provider, } \\
\text { Investigator, } \\
\text { Outcomes } \\
\text { Assessor) }\end{array}$ & $\begin{array}{l}\text { double blind, } \\
\text { Single-Center }\end{array}$ & $\begin{array}{l}\text { Open-Label, } \\
\text { Single-Center }\end{array}$ & $\begin{array}{c}\text { A Phase, I } \\
\text { Prospective, } \\
\text { Randomized, } \\
\text { Double- } \\
\text { Blinded, } \\
\text { Placebo- } \\
\text { controlled, }\end{array}$ & $\begin{array}{l}\text { Open-Label, } \\
\text { Single-Center, } \\
\text { Phase I/II }\end{array}$ \\
\hline $\begin{array}{l}\text { Estimated } \\
\text { enrollmen }\end{array}$ & 40 & 80 & 21 & 45 & 9 & 9 & 33 & 9 \\
\hline Stage & Phase lla & Phase 2b & phase $1 / 2$ & $\begin{array}{l}\text { follow up of } \\
\text { phase } 1 / 2\end{array}$ & Phase 1/2a & Phase 1 & Phase 1 & Phase 1 \\
\hline Status & Recruiting & $\begin{array}{l}\text { Not yet } \\
\text { recruiting }\end{array}$ & $\begin{array}{l}\text { Completed with } \\
\text { results }\end{array}$ & Recruiting & $\begin{array}{l}\text { Completed with } \\
\text { results }\end{array}$ & $\begin{array}{l}\text { Completed with } \\
\text { results }\end{array}$ & $\begin{array}{l}\text { Active, not } \\
\text { recruiting }\end{array}$ & Active, recruiting \\
\hline C ell type & $\begin{array}{l}\text { ischem } \\
\text { ia-tolerant } \\
\text { allogeneic } \\
\text { human }\end{array}$ & $\begin{array}{l}\text { Autologous } \\
\text { adipose tissue } \\
\text { derived }\end{array}$ & $\begin{array}{c}\text { Autologous } \\
\text { adipose tissue } \\
\text { derived }\end{array}$ & $\begin{array}{l}\text { human um } \\
\text { bilicalcord } \\
\text { blood derived }\end{array}$ & $\begin{array}{l}\text { human um } \\
\text { bilicalcord blood } \\
\text { derived }\end{array}$ & $\begin{array}{l}\text { human um } \\
\text { bilicalcord blood } \\
\text { derived }\end{array}$ & $\begin{array}{l}\text { Longeveron } \\
\text { Allogenic } \\
\text { Mesenchymal } \\
\text { Stem Cells }\end{array}$ & $\begin{array}{c}\text { Allogenic Adipose } \\
\text { Mesenchymal } \\
\text { Stem }\end{array}$ \\
\hline Cell Dosage & $\begin{array}{c}1.5 \text { million } \\
\text { cells/kg body } \\
\text { weight }\end{array}$ & $\begin{array}{c}2.0 \times 10^{-} 8 \\
\text { cells/20 mL of } \\
\text { saline with } 30 \% \\
\text { auto-serum .5 } \\
\text { m g of } \\
\text { Donepezil and } \\
\text { AstroStem } \\
\text { Placebo; via } \\
\text { intravenously } \\
\text { AstroStem and } \\
\text { Donepezil } \\
\text { Placebo every } \\
4 \text { weeks from } \\
\text { Week } 0 \text { to } \\
\text { Week } 16\end{array}$ & $\begin{array}{c}2.0 \times 10^{-} 8 \\
\text { Astrostem cells }\end{array}$ & $\begin{array}{c}\text { Low dose: } \\
1 \times 10^{-} 7 \\
\text { cells/2m L } 3 \\
\text { repeated } \\
\text { intraventricular } \\
\text { administrations } \\
\text { via an } 0 \mathrm{~mm} \\
\text { aya Reservoir at } \\
4 \text { week } \\
\text { intervals; High } \\
\text { dose: } 3 \times 10^{-} 7 \\
\text { cells }\end{array}$ & $\begin{array}{c}\text { Low dose: } \\
1 \times 10^{-} 7 \\
\text { cells } / 2 \mathrm{~m} \mathrm{~L} 3 \\
\text { repeated } \\
\text { intraventricular } \\
\text { administrations } \\
\text { via an } 0 \mathrm{~m} \text { m aya } \\
\text { Reservoir at } 4 \\
\text { week intervals; } \\
\text { High } \\
\text { dose: } 3 \times 10^{-} 7 \\
\text { cells }\end{array}$ & $\begin{array}{c}\text { dose A: } \\
2.5 \times 10^{-} 5 \text { cells } / 5 \\
\text { uL per } 1 \text { entry site, } \\
3 \times 10^{-} 6 \text { cells in } \\
\text { total per brain; dose } \\
\text { B: } 6 \times 10^{-} 6 \text { cells in } \\
\text { total per brain }\end{array}$ & $\begin{array}{l}\text { Low dose: } 20 \\
\text { million; High } \\
\text { dose: } 100 \\
\text { million } \\
\text { Longeveron } \\
\text { Mesenchymal } \\
\text { Stem Cells (LM } \\
\text { SC s) }\end{array}$ & 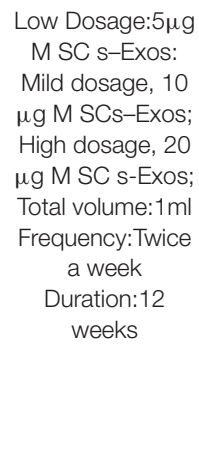 \\
\hline $\begin{array}{l}\text { Delivery } \\
\text { route }\end{array}$ & intravenous & intravenous & intravenous & $\begin{array}{l}\text { Intraventricular } \\
\text { administrations } \\
\text { via an } 0 \mathrm{~mm} \\
\text { aya Reservoir }\end{array}$ & $\begin{array}{c}\text { Intraventricular } \\
\text { administrations } \\
\text { via an } 0 \mathrm{~m} \text { m aya } \\
\text { Reservoir }\end{array}$ & $\begin{array}{c}\text { Intraventricular } \\
\text { administrations via } \\
\text { an } 0 \text { mm aya } \\
\text { Reservoir }\end{array}$ & intravenous & intravenous \\
\hline $\begin{array}{l}\text { Outcome } \\
\text { measures }\end{array}$ & $\begin{array}{c}\text { primary } \\
\text { outcome: SAE; } \\
\text { secondary } \\
\text { outcome: } \\
\text { Changes is } \\
\text { scores relatively } \\
\text { to baseline } \\
\text { using NHSS } \\
\text { system }\end{array}$ & $\begin{array}{c}\text { Primary } \\
\text { outcome: } \\
\text { ADAS-cog; } \\
\text { secondary } \\
\text { outcome M M } \\
\text { SE, A D C } \\
\text { S-CG IC, N P I, } \\
\text { Treatment } \\
\text { related Adverse } \\
\text { Events }\end{array}$ & $\begin{array}{c}\text { primary outcom } \\
\text { e: SAE; } \\
\text { ADAS-cog; } \\
\text { secondary } \\
\text { outcome:M M } \\
\text { SE,A D C S-AD } \\
\text { L. C -SSRS, N } \\
\text { PIC D R-SO } \\
\text { B,G D S }\end{array}$ & $\begin{array}{c}\text { Primary } \\
\text { outcome: } \\
\text { Number of } \\
\text { participants } \\
\text { with Adverse } \\
\text { event; } \\
\text { secondary } \\
\text { outcome: } \\
\text { Changes from } \\
\text { the baseline in } \\
\text { ADAS- cog, } \\
\text { S-IA D L, K-M } \\
\text { M SE, CG A-N } \\
\text { PI, ADAS-C og, } \\
\text { amyloid beta } \\
\text { and tau in } \\
\text { cerebrospinal } \\
\text { fluid, PIB-PET } \\
\text { and FDG -PET } \\
\text { at } 24 \text { weeks } \\
\text { post-dose. }\end{array}$ & $\begin{array}{l}\text { outcome:Number } \\
\text { of participants } \\
\text { with Adverse } \\
\text { event; secondary } \\
\text { outcome: } \\
\text { Changes from the } \\
\text { baseline in } \\
\text { ADAS-cog, } \\
\text { S-IADL, K-M M } \\
\text { SE, CGA-NPI, } \\
\text { ADAS-Cog, } \\
\text { serum } \\
\text { transthyretin, } \\
\text { amyloid beta and } \\
\text { tau in } \\
\text { cerebrospinal } \\
\text { fluid, PIB-PET } \\
\text { and FDG-PET at } \\
12 \text { weeks } \\
\text { post-dose. }\end{array}$ & $\begin{array}{l}\text { outcome: Number } \\
\text { of participants with } \\
\text { Adverse event; } \\
\text { secondary } \\
\text { outcome: Changes } \\
\text { from the baseline in } \\
\text { ADAS-cog, S-IADL, } \\
\text { K-M M SE, } \\
\text { CGA-NPI, } \\
\text { ADAS-Cog, serum } \\
\text { transthyretin, } \\
\text { amyloid beta and } \\
\text { tau in cerebrospinal } \\
\text { fluid, PIB-PET and } \\
\text { FDG-PET at } \\
12 \text { weeks } \\
\text { post-dose. }\end{array}$ & $\begin{array}{c}\text { primary } \\
\text { outcome: SAE; } \\
\text { secondary } \\
\text { outcome: } \\
\text { ADAS-Cog 11, } \\
\text { M M SE,C SF } \\
\text { and Blood } \\
\text { inflammatory } \\
\text { and A D } \\
\text { biomarkers: } \\
\text { IL-1,IL-6, } \\
\text { TGF- } \beta 1, T N \\
\text { F- } \alpha, \text { CRP, D-D } \\
\text { im er, } \\
\text { Fibrinogen, A } \\
\text { poE; Brain } \\
\text { volume try etc. }\end{array}$ & $\begin{array}{l}30 \text { days FU. No. } \\
\text { of adverse } \\
\text { events; No. of } \\
\text { adverse events 2, } \\
\text { 4, 13, 39, and } 52 \\
\text { weeks; FU } \\
\text { Change from } \\
\text { baseline: } \\
\text { ADAS-cog, M M } \\
\text { SE, adverse } \\
\text { events; No. of } \\
\text { adverse events 2, } \\
\text { 4, 13, 39, and } \\
\text { 52 weeks; FU } \\
\text { Change from } \\
\text { baseline: } \\
\text { ADAS-cog, M M } \\
\text { SE }\end{array}$ \\
\hline
\end{tabular}

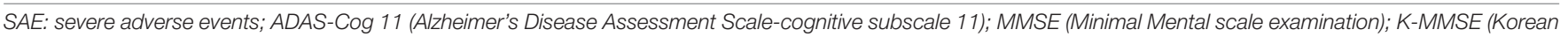

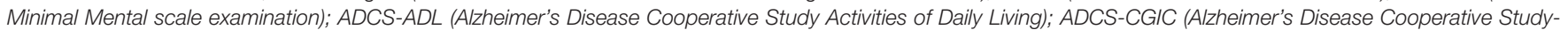

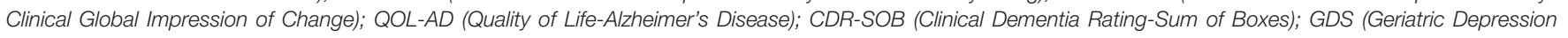
Scale); C-SSRS (Columbia Suicide Severity Rating Scale); NPI (Neuropsychiatric Inventory); CSF(cerebral spinal fluid). 
extended period of time. In some trials, autologous MSCs (for example, in those adipose tissue derived MSCs trials) were used. AD patients are usually advanced in age and autologous MSCs may suffer from senescence which compromises their regeneration capability. Most $\mathrm{AD}$ clinical trials used intravenous route. The vast majority of intravenously administered stem cells will get detained in the lung and the spleen (Park S. E. et al., 2018) and only very limited number of stem cells can get into the brain. The hostile micro-environment also hindered the survival of infused stem cells. As a result, the paracrine effects of exogenous stem cells can't compensate for the vast loss of majority neuronal cells in the patient. Anyway, there are many limitations for current MSCs clinical trials which await immediate renovation in the field.

\section{CONCLUSION AND FUTURE PERSPECTIVES}

We must look at the pathogenesis of $\mathrm{AD}$ from a dynamic point of view. $\mathrm{AD}$ has an extremely long latent period before clinical manifestation. It is this long prodromal phase which is most amenable to therapy. Early intervention has the potential to break the vicious cycle of neuronal loss and reverse the clinical course of AD. Therefore, we should make greater efforts to find novel and innovative biomarkers for this asymptomatic phase in AD. For example, disease specific exosomes, microRNAs, blood or

\section{REFERENCES}

Agrawal, I., and Jha, S. (2020). Mitochondrial Dysfunction and Alzheimer's Disease: Role of Microglia. Front. Aging Neurosci. 12:252. doi: 10.3389/fnagi. 2020.00252

Ahmad, M. H., Fatima, M., and Mondal, A. C. (2019). Influence of microglia and astrocyte activation in the neuroinflammatory pathogenesis of Alzheimer's disease: Rational insights for the therapeutic approaches. J. Clin. Neurosci. 59, 6-11. doi: 10.1016/j.jocn.2018.10.034

Almeida, O. P., Garrido, G. J., Lautenschlager, N. T., Hulse, G. K., Jamrozik, K., and Flicker, L. (2008). Smoking is associated with reduced cortical regional gray matter density in brain regions associated with incipient Alzheimer disease. Am. J. Geriatr. Psychiatry 16, 92-98. doi: 10.1097/JGP.0b013e318157cad2

Alonso, A. C., Grundke-Iqbal, I., and Iqbal, K. (1996). Alzheimer's disease hyperphosphorylated tau sequesters normal tau into tangles of filaments and disassembles microtubules. Nat. Med. 2, 783-787. doi: 10.1038/nm0796-783

Alonso, A. C., Zaidi, T., Grundke-Iqbal, I., and Iqbal, K. (1994). Role of abnormally phosphorylated tau in the breakdown of microtubules in Alzheimer disease. Proc. Natl. Acad. Sci. U S A. 91, 5562-5566. doi: 10.1073/pnas.91.12.5562

Alonso, A. D., Grundke-Iqbal, I., Barra, H. S., and Iqbal, K. (1997). Abnormal phosphorylation of tau and the mechanism of Alzheimer neurofibrillary degeneration: sequestration of microtubule-associated proteins 1 and 2 and the disassembly of microtubules by the abnormal tau. Proc. Natl. Acad. Sci. U S A. 94, 298-303. doi: 10.1073/pnas.94.1.298

Arnsten, A. F. T., Datta, D., Del Tredici, K., and Braak, H. (2021). Hypothesis: Tau pathology is an initiating factor in sporadic Alzheimer's disease. Alzheimers Dement. 17, 115-124. doi: 10.1002/alz.12192

Arvanitakis, Z., Wilson, R. S., Bienias, J. L., Evans, D. A., and Bennett, D. A. (2004). Diabetes mellitus and risk of Alzheimer disease and decline in cognitive function. Arch. Neurol. 61, 661-666. doi: 10.1001/archneur.61.5.661

Ben Haim, L., Carrillo-de Sauvage, M. A., Ceyzeriat, K., and Escartin, C. (2015). Elusive roles for reactive astrocytes in neurodegenerative diseases. Front. Cell Neurosci. 9:278. doi: 10.3389/fncel.2015.00278
CSF early disease biomarkers (especially early biomarkers for neurodegeneration), combined with improved amyloid beta and tau imaging technologies which offer better predictive values for AD (Geekiyanage et al., 2012; Olsson et al., 2016; Hansson et al., 2018; Nakamura et al., 2018).

There is so far no other therapeutic intervention that can have the pleiotropic effects of stem cells. But how to maximize the effect of stem cells to replace the missing nerve cells? In the near future, the development of stem cell based new technologies and related products will drastically change this field. For example, genetic engineering of stem cells can endorse them with stronger neurotrophic effects and greater immune-modulatory effects (Duncan and Valenzuela, 2017). The development of biological scaffolds and other new materials (Kim et al., 2020), nano-sized microvesicles and their modification technologies (Guo et al., 2020) will enable more targeted delivery and more prolonged survival of stem cells in the central nervous system. At the same time, more carefully designed AD clinical trials which target more patients in early phase or prodromal phase of the disease will likely lead to improved results in the near future.

\section{AUTHOR CONTRIBUTIONS}

JH searched the literature and wrote the review. XW reviewed the manuscript and gave helpful suggestions. Both authors contributed to the article and approved the submitted version.

Benz, C. C., and Yau, C. (2008). Ageing, oxidative stress and cancer: paradigms in parallax. Nat. Rev. Cancer 8, 875-879. doi: 10.1038/nrc2522

Berglund, R., Guerreiro-Cacais, A. O., Adzemovic, M. Z., Zeitelhofer, M., Lund, H., Ewing, E., et al. (2020). Microglial autophagy-associated phagocytosis is essential for recovery from neuroinflammation. Sci. Immunol. 5:abb5077. doi: 10.1126/sciimmunol.abb5077

Bettcher, B. M., Johnson, S. C., Fitch, R., Casaletto, K. B., Heffernan, K. S., Asthana, S., et al. (2018). Cerebrospinal Fluid and Plasma Levels of Inflammation Differentially Relate to CNS Markers of Alzheimer's Disease Pathology and Neuronal Damage. J. Alzheimers Dis. 62, 385-397. doi: 10.3233/JAD-17 0602

Bettcher, B. M., Tansey, M. G., Dorothee, G., and Heneka, M. T. (2021). Peripheral and central immune system crosstalk in Alzheimer disease - a research prospectus. Nat. Rev. Neurol. 17, 689-701. doi: 10.1038/s41582-02100549-x

Bisht, K., Sharma, K. P., Lecours, C., Sanchez, M. G., El Hajj, H., Milior, G., et al. (2016). Dark microglia: A new phenotype predominantly associated with pathological states. Glia 64, 826-839. doi: 10.1002/glia.22966

Blacker, D., Haines, J. L., Rodes, L., Terwedow, H., Go, R. C., Harrell, L. E., et al. (1997). ApoE-4 and age at onset of Alzheimer's disease: the NIMH genetics initiative. Neurology 48, 139-147. doi: 10.1212/wnl.48.1.139

Braak, H., and Braak, E. (1991). Neuropathological stageing of Alzheimer-related changes. Acta Neuropathol. 82, 239-259. doi: 10.1007/BF00308809

Caccamo, A., Branca, C., Piras, I. S., Ferreira, E., Huentelman, M. J., Liang, W. S., et al. (2017). Necroptosis activation in Alzheimer's disease. Nat. Neurosci. 20, 1236-1246. doi: 10.1038/nn.4608

Calne, D. B., Eisen, A., McGeer, E., and Spencer, P. (1986). Alzheimer's disease, Parkinson's disease, and motoneurone disease: abiotrophic interaction between ageing and environment? Lancet 2, 1067-1070. doi: 10.1016/s0140-6736(86) 90469-1

Calsolaro, V., and Edison, P. (2016). Neuroinflammation in Alzheimer's disease: Current evidence and future directions. Alzheimers Dement. 12, 719-732. doi: 10.1016/j.jalz.2016.02.010 
Calvo-Rodriguez, M., Garcia-Rodriguez, C., Villalobos, C., and Nunez, L. (2020). Role of Toll Like Receptor 4 in Alzheimer's Disease. Front. Immunol. 11:1588. doi: 10.3389/fimmu.2020.01588

Carranza-Naval, M. J., Vargas-Soria, M., Hierro-Bujalance, C., Baena-Nieto, G., Garcia-Alloza, M., Infante-Garcia, C., et al. (2021). Alzheimer's Disease and Diabetes: Role of Diet, Microbiota and Inflammation in Preclinical Models. Biomolecules 11:biom11020262. doi: 10.3390/biom11020262

Casserly, I., and Topol, E. (2004). Convergence of atherosclerosis and Alzheimer's disease: inflammation, cholesterol, and misfolded proteins. Lancet 363, 1139 1146. doi: 10.1016/s0140-6736(04)15900-X

Chang, K. H., Hsu, Y. C., Hsu, C. C., Lin, C. L., Hsu, C. Y., Lee, C. Y., et al. (2016). Prolong Exposure of NSAID in Patients With RA Will Decrease the Risk of Dementia: A Nationwide Population-Based Cohort Study. Medicine 95:e3056. doi: 10.1097/MD.0000000000003056

Chen, Y. A., Lu, C. H., Ke, C. C., and Liu, R. S. (2021). Mesenchymal Stem CellDerived Extracellular Vesicle-Based Therapy for Alzheimer's Disease: Progress and Opportunity. Membranes 11:11100796. doi: 10.3390/membranes11100796

Chiarini, A., Armato, U., Hu, P., and Dal Pra, I. (2020). Danger-Sensing/Patten Recognition Receptors and Neuroinflammation in Alzheimer's Disease. Int. J. Mol. Sci. 21:21239036. doi: 10.3390/ijms21239036

Chun, H., Im, H., Kang, Y. J., Kim, Y., Shin, J. H., Won, W., et al. (2020). Severe reactive astrocytes precipitate pathological hallmarks of Alzheimer's disease via H2O2(-) production. Nat. Neurosci. 23, 1555-1566. doi: 10.1038/s41593-02000735-y

Cuello, A. C. (2017). Early and Late CNS Inflammation in Alzheimer's Disease: Two Extremes of a Continuum? Trends Pharmacol. Sci. 38, 956-966. doi: 10. 1016/j.tips.2017.07.005

Cummings, J., Lee, G., Ritter, A., Sabbagh, M., and Zhong, K. (2020). Alzheimer's disease drug development pipeline: 2020. Alzheimers Dement. 6:e12050. doi: $10.1002 / \operatorname{trc} 2.12050$

Daynac, M., Pineda, J. R., Chicheportiche, A., Gauthier, L. R., Morizur, L., Boussin, F. D., et al. (2014). TGF $\beta$ lengthens the G1 phase of stem cells in aged mouse brain. Stem Cells 32, 3257-3265. doi: 10.1002/stem.1815

Deczkowska, A., Keren-Shaul, H., Weiner, A., Colonna, M., Schwartz, M., and Amit, I. (2018). Disease-Associated Microglia: A Universal Immune Sensor of Neurodegeneration. Cell 173, 1073-1081. doi: 10.1016/j.cell.2018.05.003

Di Marco, L. Y., Venneri, A., Farkas, E., Evans, P. C., Marzo, A., and Frangi, A. F. (2015). Vascular dysfunction in the pathogenesis of Alzheimer's diseaseA review of endothelium-mediated mechanisms and ensuing vicious circles. Neurobiol. Dis. 82, 593-606. doi: 10.1016/j.nbd.2015.08.014

Dioguardi, M., Crincoli, V., Laino, L., Alovisi, M., Sovereto, D., Mastrangelo, F., et al. (2020). The Role of Periodontitis and Periodontal Bacteria in the Onset and Progression of Alzheimer's Disease: A Systematic Review. J. Clin. Med. 9:9020495. doi: 10.3390/jcm9020495

Dominici, M., Le Blanc, K., Mueller, I., Slaper-Cortenbach, I., Marini, F., Krause, D., et al. (2006). Minimal criteria for defining multipotent mesenchymal stromal cells. The International Society for Cellular Therapy position statement. Cytotherapy 8, 315-317.

Dulken, B. W., Buckley, M. T., Navarro Negredo, P., Saligrama, N., Cayrol, R., Leeman, D. S., et al. (2019). Single-cell analysis reveals T cell infiltration in old neurogenic niches. Nature 571, 205-210.

Duncan, T., and Valenzuela, M. (2017). Alzheimer's disease, dementia, and stem cell therapy. Stem Cell Res. Ther. 8:111. doi: 10.1186/s13287-017-0567-5

Duyckaerts, C., Clavaguera, F., and Potier, M. C. (2019). The prion-like propagation hypothesis in Alzheimer's and Parkinson's disease. Curr. Opin. Neurol. 32, 266-271. doi: 10.1097/wco.0000000000000672

Edwards, F. A. (2019). A Unifying Hypothesis for Alzheimer's Disease: From Plaques to Neurodegeneration. Trends Neurosci. 42, 310-322. doi: 10.1016/j. tins.2019.03.003

Ennerfelt, H. E., and Lukens, J. R. (2020). The role of innate immunity in Alzheimer's disease. Immunol. Rev. 297, 225-246. doi: 10.1111/imr.12896

Fielder, E., Tweedy, C., Wilson, C., Oakley, F., LeBeau, F. E. N., Passos, J. F., et al. (2020). Anti-inflammatory treatment rescues memory deficits during aging in nfkb1 ${ }^{-/-}$mice. Aging Cell 19:e13188. doi: 10.1111/acel.13188

Fleming, A., and Rubinsztein, D. C. (2020). Autophagy in Neuronal Development and Plasticity. Trends Neurosci. 43, 767-779.

Franceschi, C., Capri, M., Monti, D., Giunta, S., Olivieri, F., Sevini, F., et al. (2007). Inflammaging and anti-inflammaging: a systemic perspective on aging and longevity emerged from studies in humans. Mech. Ageing Dev. 128, 92-105. doi: 10.1016/j.mad.2006.11.016

François, A., Rioux, B. A., Quellard, N., Fernandez, B., Janet, T., Chassaing, D., et al. (2014). Longitudinal follow-up of autophagy and inflammation in brain of APPswePS1dE9 transgenic mice. J. Neuroinflamm. 11:139.

Friedenstein, A. J., Chailakhyan, R. K., Latsinik, N. V., Panasyuk, A. F., and Keiliss-Borok, I. V. (1974). Stromal cells responsible for transferring the microenvironment of the hemopoietic tissues. Cloning in vitro and retransplantation in vivo. Transplantation 17, 331-340. doi: 10.1097/00007890197404000-00001

Friedland, R. P. (2015). Mechanisms of molecular mimicry involving the microbiota in neurodegeneration. J. Alzheimers Dis. 45, 349-362. doi: 10.3233/ JAD- 142841

Gage, F. H. (2000). Mammalian neural stem cells. Science 287, 1433-1438. doi: 10.1126/science.287.5457.1433

Gambuzza, M. E., Sofo, V., Salmeri, F. M., Soraci, L., Marino, S., and Bramanti, P. (2014). Toll-like receptors in Alzheimer's disease: a therapeutic perspective. CNS Neurol. Disord. Drug Targets 13, 1542-1558. doi: 10.2174/ 1871527313666140806124850

Geekiyanage, H., Jicha, G. A., Nelson, P. T., and Chan, C. (2012). Blood serum miRNA: non-invasive biomarkers for Alzheimer's disease. Exp. Neurol. 235, 491-496. doi: 10.1016/j.expneurol.2011.11.026

Giunta, B., Fernandez, F., Nikolic, W. V., Obregon, D., Rrapo, E., Town, T., et al. (2008). Inflammaging as a prodrome to Alzheimer's disease. J. Neuroinflamm. 5:51. doi: 10.1186/1742-2094-5-51

Goate, A., Chartier-Harlin, M. C., Mullan, M., Brown, J., Crawford, F., Fidani, L., et al. (1991). Segregation of a missense mutation in the amyloid precursor protein gene with familial Alzheimer's disease. Nature 349, 704-706. doi: 10. 1038/349704a0

Gomzikova, M. O., James, V., and Rizvanov, A. A. (2021). Mitochondria Donation by Mesenchymal Stem Cells: Current Understanding and Mitochondria Transplantation Strategies. Front. Cell Dev. Biol. 9:653322. doi: 10.3389/fcell. 2021.653322

Grant, W. B. (2004). Obesity and Alzheimer disease: roles of diet and genetics. Arch. Intern. Med. 164, 109-110. doi: 10.1001/archinte.164.1.109-b

Gratuze, M., Leyns, C. E. G., and Holtzman, D. M. (2018). New insights into the role of TREM2 in Alzheimer's disease. Mol. Neurodegener. 13:66. doi: 10.1186/ s13024-018-0298-9

Griciuc, A., Patel, S., Federico, A. N., Choi, S. H., Innes, B. J., Oram, M. K., et al. (2019). TREM2 Acts Downstream of CD33 in Modulating Microglial Pathology in Alzheimer's Disease. Neuron 103, 820-835e827. doi: 10.1016/j.neuron.2019. 06.010

Guerreiro, R., Wojtas, A., Bras, J., Carrasquillo, M., Rogaeva, E., Majounie, E., et al. (2012). TREM2 Variants in Alzheimer's Disease. Cell 368, 117-127. doi: 10.1056/NEJMoa1211851

Guo, M., Yin, Z., Chen, F., and Lei, P. (2020). Mesenchymal stem cellderived exosome: a promising alternative in the therapy of Alzheimer's disease. Alzheimers Res. Ther. 12:109. doi: 10.1186/s13195-02000670-x

Guo, W., Zeng, Z., Xing, C., Zhang, J., Bi, W., Yang, J., et al. (2021). Stem cells from human exfoliated deciduous teeth affect mitochondria and reverse cognitive decline in a senescence-accelerated mouse prone 8 model. Cytotherapy 2021:18. doi: 10.1016/j.jcyt.2021.07.018

Hachinski, V. (1998). Aluminum exposure and risk of Alzheimer disease. Arch. Neurol. 55:742. doi: 10.1001/archneur.55.5.742

Hansson, O., Seibyl, J., Stomrud, E., Zetterberg, H., Trojanowski, J. Q., Bittner, T., et al. (2018). CSF biomarkers of Alzheimer's disease concord with amyloid-beta PET and predict clinical progression: A study of fully automated immunoassays in BioFINDER and ADNI cohorts. Alzheimers Dement. 14, 1470-1481. doi: 10.1016/j.jalz.2018.01.010

Harbi, D., and Harrison, P. M. (2014). Classifying prion and prion-like phenomena. Prion 8, 161-165. doi: 10.4161/pri.27960

Hardy, J. A., and Higgins, G. A. (1992). Alzheimer's disease: the amyloid cascade hypothesis. Science 256, 184-185. doi: 10.1126/science.1566067

Harold, D., Abraham, R., Hollingworth, P., Sims, R., Gerrish, A., Hamshere, M. L., et al. (2009). Genome-wide association study identifies variants at CLU and PICALM associated with Alzheimer's disease. Nat. Genet. 41, 1088-1093. doi: $10.1038 /$ ng.440 
Hayakawa, K., Esposito, E., Wang, X., Terasaki, Y., Liu, Y., Xing, C., et al. (2016). Transfer of mitochondria from astrocytes to neurons after stroke. Nature 535, 551-555.

Heneka, M. T., Carson, M. J., El Khoury, J., Landreth, G. E., Brosseron, F., Feinstein, D. L., et al. (2015). Neuroinflammation in Alzheimer's disease. Lancet Neurol. 14, 388-405. doi: 10.1016/S1474-4422(15)70016-5

Hernandez, A. E., and Garcia, E. (2021). Mesenchymal Stem Cell Therapy for Alzheimer's Disease. Stem Cells Int. 2021:7834421. doi: 10.1155/2021/783 4421

Hollingworth, P., Harold, D., Sims, R., Gerrish, A., Lambert, J. C., Carrasquillo, M. M., et al. (2011). Common variants at ABCA7, MS4A6A/MS4A4E, EPHA1, CD33 and CD2AP are associated with Alzheimer's disease. Nat. Genet. 43, 429-435. doi: 10.1038/ng.803

Hoye, A. T., Davoren, J. E., Wipf, P., Fink, M. P., and Kagan, V. E. (2008). Targeting mitochondria. Accounts Chem. Res. 41, 87-97. doi: 10.1021/ar700 $135 \mathrm{~m}$

Huang, L., Reis, C., Boling, W. W., and Zhang, J. H. (2020). Stem Cell Therapy in Brain Ischemia: The Role of Mitochondrial Transfer. Stem Cells Dev. 29, 555-561. doi: 10.1089/scd.2019.0237

Huang, Z., Wong, L. W., Su, Y., Huang, X., Wang, N., Chen, H., et al. (2020). Blood-brain barrier integrity in the pathogenesis of Alzheimer's disease. Front. Neuroendocrinol. 59:100857. doi: 10.1016/j.yfrne.2020.100857

Ilievski, V., Zuchowska, P. K., Green, S. J., Toth, P. T., Ragozzino, M. E., Le, K., et al. (2018). Chronic oral application of a periodontal pathogen results in brain inflammation, neurodegeneration and amyloid beta production in wild type mice. PLoS One 13:e0204941. doi: 10.1371/journal.pone. 0204941

Iqbal, K., Grundke-Iqbal, I., Zaidi, T., Merz, P. A., Wen, G. Y., Shaikh, S. S., et al. (1986). Defective brain microtubule assembly in Alzheimer's disease. Lancet 2, 421-426. doi: 10.1016/s0140-6736(86)92134-3

Iqbal, K., Liu, F., Gong, C. X., and Grundke-Iqbal, I. (2010). Tau in Alzheimer disease and related tauopathies. Curr. Alzheimer Res. 7, 656-664. doi: 10.2174/ 156720510793611592

Jack, C. R. Jr., Bennett, D. A., Blennow, K., Carrillo, M. C., Dunn, B., Haeberlein, S. B., et al. (2018). NIA-AA Research Framework: Toward a biological definition of Alzheimer's disease. Alzheimers Dement. 14, 535-562. doi: 10.1016/j.jalz. 2018.02.018

Jayaraman, A., Htike, T. T., James, R., Picon, C., and Reynolds, R. (2021). TNFmediated neuroinflammation is linked to neuronal necroptosis in Alzheimer's disease hippocampus. Acta Neuropathol. Commun. 9:159. doi: 10.1186/s40478021-01264-w

Jin, W. N., Shi, K., He, W., Sun, J. H., Van Kaer, L., Shi, F. D., et al. (2021). Neuroblast senescence in the aged brain augments natural killer cell cytotoxicity leading to impaired neurogenesis and cognition. Nat. Neurosci. 24, 61-73. doi: 10.1038/s41593-020-00745-w

Kane, M. D., Lipinski, W. J., Callahan, M. J., Bian, F., Durham, R. A., Schwarz, R. D., et al. (2000). Evidence for seeding of beta -amyloid by intracerebral infusion of Alzheimer brain extracts in beta -amyloid precursor protein-transgenic mice. J. Neurosci. Offic. J. Soc. Neurosci. 20, 3606-3611. doi: 10.1523/jneurosci.20-1003606.2000

Karran, E., and De Strooper, B. (2016). The amyloid cascade hypothesis: are we poised for success or failure? J. Neurochem. 139(Suppl. 2), 237-252. doi: 10. 1111/jnc. 13632

Katzman, R., Terry, R., DeTeresa, R., Brown, T., Davies, P., Fuld, P., et al. (1988). Clinical, pathological, and neurochemical changes in dementia: a subgroup with preserved mental status and numerous neocortical plaques. Ann. Neurol. 23, 138-144. doi: 10.1002/ana.410230206

Kaur, D., Sharma, V., and Deshmukh, R. (2019). Activation of microglia and astrocytes: a roadway to neuroinflammation and Alzheimer's disease. Inflammopharmacology 27, 663-677. doi: 10.1007/s10787-019-00580-x

Keren-Shaul, H., Spinrad, A., Weiner, A., Matcovitch-Natan, O., Dvir-Szternfeld, R., Ulland, T. K., et al. (2017). A Unique Microglia Type Associated with Restricting Development of Alzheimer's Disease. Cell 169, 1276-1290e17.

Kim, J. Y., Kim, D. H., Kim, J. H., Lee, D., Jeon, H. B., Kwon, S. J., et al. (2012). Soluble intracellular adhesion molecule-1 secreted by human umbilical cord blood-derived mesenchymal stem cell reduces amyloid- $\beta$ plaques. Cell Death Different. 19, 680-691. doi: 10.1038/cdd.2011.140
Kim, J., Lee, Y., Lee, S., Kim, K., Song, M., and Lee, J. (2020). Mesenchymal Stem Cell Therapy and Alzheimer's Disease: Current Status and Future Perspectives. J. Alzheimers Dis. 77, 1-14. doi: 10.3233/JAD-200219

Kinney, J. W., Bemiller, S. M., Murtishaw, A. S., Leisgang, A. M., Salazar, A. M., and Lamb, B. T. (2018). Inflammation as a central mechanism in Alzheimer's disease. Alzheimers Dement 4, 575-590. doi: 10.1016/j.trci.2018.06.014

Kirkland, J. L., and Tchkonia, T. (2017). Cellular Senescence: A Translational Perspective. EBioMedicine 21, 21-28. doi: 10.1016/j.ebiom.2017.04.013

Kokoeva, M. V., Yin, H., and Flier, J. S. (2005). Neurogenesis in the hypothalamus of adult mice: potential role in energy balance. Science 310, 679-683. doi: 10 . 1126/science. 1115360

Kolagar, T. A., Farzaneh, M., Nikkar, N., and Khoshnam, S. E. (2020). Human Pluripotent Stem Cells in Neurodegenerative Diseases: Potentials, Advances and Limitations. Curr. Stem Cell Res. Ther. 15, 102-110. doi: 10.2174/ 1574888X14666190823142911

Korhonen, P., Malm, T., and White, A. R. (2018). 3D human brain cell models: New frontiers in disease understanding and drug discovery for neurodegenerative diseases. Neurochem. Int. 120, 191-199. doi: 10.1016/j.neuint.2018.08.012

Kuang, H., Tan, C. Y., Tian, H. Z., Liu, L. H., Yang, M. W., Hong, F. F., et al. (2020). Exploring the bi-directional relationship between autophagy and Alzheimer's disease. CNS Neurosci. Ther. 26, 155-166. doi: 10.1111/cns.13216

Kwon, H. S., and Koh, S. H. (2020). Neuroinflammation in neurodegenerative disorders: the roles of microglia and astrocytes. Transl. Neurodegener. 9:42. doi: 10.1186/s40035-020-00221-2

Laval, K., and Enquist, L. W. (2021). The Potential Role of Herpes Simplex Virus Type 1 and Neuroinflammation in the Pathogenesis of Alzheimer's Disease. Front. Neurol. 12:658695. doi: 10.3389/fneur.2021.658695

Li, Q., Liu, Y., and Sun, M. (2017). Autophagy and Alzheimer's Disease. Cell Mol. Neurobiol. 37, 377-388. doi: 10.1007/s10571-016-0386-8

Liddelow, S. A., Guttenplan, K. A., Clarke, L. E., Bennett, F. C., Bohlen, C. J., Schirmer, L., et al. (2017). Neurotoxic reactive astrocytes are induced by activated microglia. Nature 541, 481-487. doi: 10.1038/nature21029

Liu, H., Zhang, H., and Ma, Y. (2021). Molecular mechanisms of altered adult hippocampal neurogenesis in Alzheimer's disease. Mech. Ageing Dev. 195:111452. doi: 10.1016/j.mad.2021.111452

Liu, K., Guo, L., Zhou, Z., Pan, M., and Yan, C. (2019). Mesenchymal stem cells transfer mitochondria into cerebral microvasculature and promote recovery from ischemic stroke. Microvasc. Res. 123, 74-80. doi: 10.1016/j.mvr.2019. 01.001

Ma, T., Gong, K., Ao, Q., Yan, Y., Song, B., Huang, H., et al. (2013). Intracerebral transplantation of adipose-derived mesenchymal stem cells alternatively activates microglia and ameliorates neuropathological deficits in Alzheimer's disease mice. Cell Transplant. 22(Suppl. 1), S113-S126. doi: 10. 3727/096368913X672181

McGeer, P. L., and Rogers, J. (1992). Anti-inflammatory agents as a therapeutic approach to Alzheimer's disease. Neurology 42, 447-449. doi: 10.1212/wnl.42. 2.447

McGeer, P. L., Itagaki, S., Tago, H., and McGeer, E. G. (1987). Reactive microglia in patients with senile dementia of the Alzheimer type are positive for the histocompatibility glycoprotein HLA-DR. Neurosci. Lett. 79, 195-200. doi: 10. 1016/0304-3940(87)90696-3

Megur, A., Baltriukiene, D., Bukelskiene, V., and Burokas, A. (2020). The Microbiota-Gut-Brain Axis and Alzheimer's Disease: Neuroinflammation Is to Blame? Nutrients 13:13010037. doi: 10.3390/nu13010037

Meyer, P. F., Savard, M., Poirier, J., Labonte, A., Rosa-Neto, P., Weitz, T. M., et al. (2018). Bi-directional Association of Cerebrospinal Fluid Immune Markers with Stage of Alzheimer's Disease Pathogenesis. J. Alzheimers Dis. 63, 577-590. doi: 10.3233/JAD-170887

Moreno-Jimenez, E. P., Terreros-Roncal, J., Flor-Garcia, M., Rabano, A., and Llorens-Martin, M. (2021). Evidences for Adult Hippocampal Neurogenesis in Humans. J. Neurosci. 41, 2541-2553. doi: 10.1523/JNEUROSCI.0675-20.2020

Mortimer, J. A., Snowdon, D. A., and Markesbery, W. R. (2008). Small head circumference is associated with less education in persons at risk for Alzheimer disease in later life. Alzheimer Dis. Assoc. Disord. 22, 249-254. doi: 10.1097/ WAD.0b013e318170d455

Muñoz-Espín, D., and Serrano, M. (2014). Cellular senescence: from physiology to pathology. Nat. Rev. Mol. Cell Biol. 15, 482-496. doi: 10.1038/nrm3823 
Naaldijk, Y., Jager, C., Fabian, C., Leovsky, C., Bluher, A., Rudolph, L., et al. (2017). Effect of systemic transplantation of bone marrow-derived mesenchymal stem cells on neuropathology markers in APP/PS1 Alzheimer mice. Neuropathol. Appl. Neurobiol. 43, 299-314. doi: 10.1111/nan.12319

Nakamura, A., Kaneko, N., Villemagne, V. L., Kato, T., Doecke, J., Dore, V., et al. (2018). High performance plasma amyloid-beta biomarkers for Alzheimer's disease. Nature 554, 249-254. doi: 10.1038/nature25456

Navarro Negredo, P., Yeo, R. W., and Brunet, A. (2020). Aging and Rejuvenation of Neural Stem Cells and Their Niches. Cell Stem Cell 27, 202-223. doi: 10.1016/ j.stem.2020.07.002

Olsson, B., Lautner, R., Andreasson, U., Öhrfelt, A., Portelius, E., Bjerke, M., et al. (2016). CSF and blood biomarkers for the diagnosis of Alzheimer's disease: a systematic review and meta-analysis. Lancet Neurol. 15, 673-684. doi: 10.1016/ s1474-4422(16)00070-3

Onyango, I. G., Jauregui, G. V., Carna, M., Bennett, J. P. Jr., and Stokin, G. B. (2021). Neuroinflammation in Alzheimer's Disease. Biomedicines 9:9050524. doi: 10.3390/biomedicines 9050524

Ou, Y. N., Tan, C. C., Shen, X. N., Xu, W., Hou, X. H., Dong, Q., et al. (2020). Blood Pressure and Risks of Cognitive Impairment and Dementia: A Systematic Review and Meta-Analysis of 209 Prospective Studies. Hypertension 76, $217-$ 225. doi: 10.1161/hypertensionaha.120.14993

Park, B. N., Kim, J. H., Lim, T. S., Park, S. H., Kim, T. G., Yoon, B. S., et al. (2020). Therapeutic effect of mesenchymal stem cells in an animal model of Alzheimer's disease evaluated by beta-amyloid positron emission tomography imaging. Aust. N Z J. Psychiatry 54, 883-891. doi: 10.1177/000486742091 7467

Park, B. N., Lim, T. S., Yoon, J. K., and An, Y. S. (2018). In vivo tracking of intravenously injected mesenchymal stem cells in an Alzheimer's animal model. Cell Transplant. 27, 1203-1209. doi: 10.1177/096368971878 8067

Park, S. E., Lee, N. K., Na, D. L., and Chang, J. W. (2018). Optimal mesenchymal stem cell delivery routes to enhance neurogenesis for the treatment of Alzheimer's disease: optimal MSCs delivery routes for the treatment of AD. Histol. Histopathol. 33, 533-541. doi: 10.14670/HH-11-950

Patterson, C. (2018). World Alzheimer Report 2018:The state of the art of dementia research: New frontiers. London: Alzheimer's Disease International.

Preman, P., Alfonso-Triguero, M., Alberdi, E., Verkhratsky, A., and Arranz, A. M. (2021). Astrocytes in Alzheimer's Disease: Pathological Significance and Molecular Pathways. Cells 10:10030540. doi: 10.3390/cells1003 0540

Prince, M., C-Ha, Knapp, M., Guerchet, M., and Karagiannidou, M. (2016). World Alzheimer Report 2016: Improving Healthcare for People Living With Dementia: Coverage, Quality and Costs Now and in the Future. London: Alzheimer's Disease International (ADI).

Qin, C., Li, Y., and Wang, K. (2021). Functional Mechanism of Bone MarrowDerived Mesenchymal Stem Cells in the Treatment of Animal Models with Alzheimer's Disease: Inhibition of Neuroinflammation. J. Inflamm. Res. 14, 4761-4775.

Ries, M., and Sastre, M. (2016). Mechanisms of Abeta Clearance and Degradation by Glial Cells. Front. Aging Neurosci. 8:160. doi: 10.3389/fnagi.2016.00160

Rogaev, E. I., Sherrington, R., Rogaeva, E. A., Levesque, G., Ikeda, M., Liang, Y., et al. (1995). Familial Alzheimer's disease in kindreds with missense mutations in a gene on chromosome 1 related to the Alzheimer's disease type 3 gene. Nature 376, 775-778. doi: 10.1038/376775a0

Rosenberg, G. A. (2012). Neurological diseases in relation to the blood-brain barrier. J. Cereb. Blood Flow Metab. 32, 1139-1151. doi: 10.1038/jcbfm.2011.197

Sabbagh, M. N. (2020). Editorial: Alzheimer's Disease Drug Development Pipeline 2020. J. Prev. Alzheimers Dis. 7, 66-67. doi: 10.14283/jpad.2020.12

Santamaria, G., Brandi, E., Vitola, P., Grandi, F., Ferrara, G., Pischiutta, F., et al. (2021). Intranasal delivery of mesenchymal stem cell secretome repairs the brain of Alzheimer's mice. Cell Death Differ. 28, 203-218. doi: 10.1038/s41418020-0592-2

Sapolsky, R. M., Krey, L. C., and McEwen, B. S. (1986). The neuroendocrinology of stress and aging: the glucocorticoid cascade hypothesis. Endocr. Rev. 7, 284-301. doi: 10.1210/edrv-7-3-284

Sarlus, H., and Heneka, M. T. (2017). Microglia in Alzheimer's disease. J. Clin. Invest. 127, 3240-3249. doi: 10.1172/JCI90606
Scherzer, C. R., Offe, K., Gearing, M., Rees, H. D., Fang, G., Heilman, C. J., et al. (2004). Loss of Apolipoprotein E Receptor LR11 in Alzheimer Disease. Arch. Neurol. 61, 1200-1205.

Selkoe, D. J. (1994). Normal and abnormal biology of the beta-amyloid precursor protein. Annu. Rev. Neurosci. 17, 489-517. doi: 10.1146/annurev.ne.17.030194. 002421

Sherrington, R., Rogaev, E. I., Liang, Y., Rogaeva, E. A., Levesque, G., Ikeda, M., et al. (1995). Cloning of a gene bearing missense mutations in early-onset familial Alzheimer's disease. Nature 375, 754-760. doi: 10.1038/375754a0

Singh, A., Kukreti, R., Saso, L., and Kukreti, S. (2019). Oxidative Stress: A Key Modulator in Neurodegenerative Diseases. Molecules 24:24081583. doi: 10. 3390/molecules24081583

Sivandzade, F., and Cucullo, L. (2021). Regenerative Stem Cell Therapy for Neurodegenerative Diseases: An Overview. Int. J. Mol. Sci. 22:2153.

Skoog, I., Kalaria, R. N., and Breteler, M. M. (1999). Vascular factors and Alzheimer disease. Alzheimer Dis. Assoc. Disord. 13(Suppl. 3), S106-S114. doi: 10.1097/ 00002093-199912003-00016

Snowdon, D. A., Greiner, L. H., Mortimer, J. A., Riley, K. P., Greiner, P. A., and Markesbery, W. R. (1997). Brain infarction and the clinical expression of Alzheimer disease. Nun Study JAMA. 277, 813-817.

Sullivan, P., Petitti, D., and Barbaccia, J. (1987). Head trauma and age of onset of dementia of the Alzheimer type. JAMA 257, 2289-2290. doi: 10.1001/jama.1987. 03390170045014

Tarantini, S., Tran, C. H. T., Gordon, G. R., Ungvari, Z., and Csiszar, A. (2017). Impaired neurovascular coupling in aging and Alzheimer's disease: Contribution of astrocyte dysfunction and endothelial impairment to cognitive decline. Exp. Gerontol. 94, 52-58. doi: 10.1016/j.exger.2016. 11.004

Teixeira, F. B., Saito, M. T., Matheus, F. C., Prediger, R. D., Yamada, E. S., Maia, C. S. F., et al. (2017). Periodontitis and Alzheimer's Disease: A Possible Comorbidity between Oral Chronic Inflammatory Condition and Neuroinflammation. Front. Aging Neurosci. 9:327. doi: 10.3389/fnagi.2017. 00327

Thomas, R., Wang, W., and Su, D. M. (2020). Contributions of Age-Related Thymic Involution to Immunosenescence and Inflammaging. Immun. Ageing I \& A 17:2. doi: 10.1186/s12979-020-0173-8

Tobin, M. K., Musaraca, K., Disouky, A., Shetti, A., Bheri, A., Honer, W. G., et al. (2019). Human Hippocampal Neurogenesis Persists in Aged Adults and Alzheimer's Disease Patients. Cell Stem Cell. 24, 974-982e973. doi: 10.1016/j. stem.2019.05.003

Tonnies, E., and Trushina, E. (2017). Oxidative Stress, Synaptic Dysfunction, and Alzheimer's Disease. J. Alzheimers Dis. 57, 1105-1121. doi: 10.3233/JAD161088

Ulland, T. K., and Colonna, M. (2018). TREM2 - a key player in microglial biology and Alzheimer disease. Nat. Rev. Neurol. 14, 667-675. doi: 10.1038/s41582-0180072-1

Walker, L. C., and Jucker, M. (2015). Neurodegenerative diseases: expanding the prion concept. Annu. Rev. Neurosci. 38, 87-103. doi: 10.1146/annurev-neuro071714-033828

Walter, S., Letiembre, M., Liu, Y., Heine, H., Penke, B., Hao, W., et al. (2007). Role of the toll-like receptor 4 in neuroinflammation in Alzheimer's disease. Cell Physiol. Biochem. 20, 947-956. doi: 10.1159/000110455

Wang, S. Y., Gong, P. Y., Zhang, Y. D., and Jiang, T. (2020). The Role of TREML2 in Alzheimer's Disease. J Alzheimers Dis. 76, 799-806. doi: 10.3233/JAD-200406

Wang, X., and Gerdes, H. H. (2015). Transfer of mitochondria via tunneling nanotubes rescues apoptotic PC12 cells. Cell Death Differ. 22, 1181-1191. doi: 10.1038/cdd.2014.211

Wang, Y., Lin, Y., Wang, L., Zhan, H., Luo, X., Zeng, Y., et al. (2020). TREM2 ameliorates neuroinflammatory response and cognitive impairment via PI3K/AKT/FoxO3a signaling pathway in Alzheimer's disease mice. Aging12, 20862-20879. doi: 10.18632/aging.104104

Wei, Y., Xie, Z., Bi, J., and Zhu, Z. (2018). Anti-inflammatory effects of bone marrow mesenchymal stem cells on mice with Alzheimer's disease. Exp. Therapeut. Med. 2018:6857. doi: 10.3892/etm.2018.6857

Wingo, T. S., Lah, J. J., Levey, A. I., and Cutler, D. J. (2012). Autosomal recessive causes likely in early-onset Alzheimer disease. Arch. Neurol. 69, 59-64. doi: 10.1001/archneurol.2011.221 
Wolfe, C. M., Fitz, N. F., Nam, K. N., Lefterov, I., and Koldamova, R. (2018). The Role of APOE and TREM2 in Alzheimer's Disease-Current Understanding and Perspectives. Int. J. Mol. Sci. 20:ijms20010081. doi: 10.3390/ijms20010081

Xie, Z. H., Liu, Z., Zhang, X. R., Yang, H., Wei, L. F., Wang, Y., et al. (2016). Wharton's Jelly-derived mesenchymal stem cells alleviate memory deficits and reduce amyloid-beta deposition in an APP/PS1 transgenic mouse model. Clin. Exp. Med. 16, 89-98. doi: 10.1007/s10238-015-0375-0

$\mathrm{Xu}$, H., and Jia, J. (2021). Single-Cell RNA Sequencing of Peripheral Blood Reveals Immune Cell Signatures in Alzheimer's Disease. Front. Immunol. 12:645666. doi: 10.3389/fimmu.2021.645666

Xu, Z. Q., Zhang, L. Q., Wang, Q., Marshall, C., Xiao, N., Gao, J. Y., et al. (2013). Aerobic exercise combined with antioxidative treatment does not counteract moderate- or mid-stage Alzheimer-like pathophysiology of APP/PS1 mice. CNS Neurosci. Ther. 19, 795-803. doi: 10.1111/cns.12139

Yamazaki, Y., Baker, D. J., Tachibana, M., Liu, C. C., van Deursen, J. M., Brott, T. G., et al. (2016). Vascular Cell Senescence Contributes to Blood-Brain Barrier Breakdown. Stroke 47, 1068-1077. doi: 10.1161/strokeaha.115.0 10835

Yan, Y., Ma, T., Gong, K., Ao, Q., Zhang, X., and Gong, Y. (2014). Adiposederived mesenchymal stem cell transplantation promotes adult neurogenesis in the brains of Alzheimer's disease mice. Neural Regen. Res. 9, 798-805. doi: 10.4103/1673-5374.131596

Yoo, S. M., Park, J., Kim, S. H., and Jung, Y. K. (2020). Emerging perspectives on mitochondrial dysfunction and inflammation in Alzheimer's disease. BMB Rep. $53,35-46$.

Zhang, L., Dong, Z. F., and Zhang, J. Y. (2020). Immunomodulatory role of mesenchymal stem cells in Alzheimer's disease. Life Sci. 246:117405. doi: 10. 1016/j.lfs.2020.117405

Zhang, Y., Fung, I. T. H., Sankar, P., Chen, X., Robison, L. S., Ye, L., et al. (2020). Depletion of NK cells improves cognitive function in the Alzheimer disease mouse model. J. Immunol. 205, 502-510. doi: 10.4049/jimmunol.2000037
Zhang, Z., Sheng, H., Liao, L., Xu, C., Zhang, A., Yang, Y., et al. (2020). Mesenchymal Stem Cell-Conditioned Medium Improves Mitochondrial Dysfunction and Suppresses Apoptosis in Okadaic Acid-Treated SH-SY5Y Cells by Extracellular Vesicle Mitochondrial Transfer. J. Alzheimer's Dis. 78, 1161-1176. doi: 10.3233/jad-200686

Zhao, Y., Chen, X., Wu, Y., Wang, Y., Li, Y., and Xiang, C. (2018). Transplantation of Human Menstrual Blood-Derived Mesenchymal Stem Cells Alleviates Alzheimer's Disease-Like Pathology in APP/PS1 Transgenic Mice. Front. Mol. Neurosci. 11:140. doi: 10.3389/fnmol.2018.00140

Zuo, L., Prather, E. R., Stetskiv, M., Garrison, D. E., Meade, J. R., Peace, T. I., et al. (2019). Inflammaging and Oxidative Stress in Human Diseases: From Molecular Mechanisms to Novel Treatments. Int. J. Mol. Sci. 20:ijms20184472. doi: $10.3390 /$ ijms 20184472

Conflict of Interest: The authors declare that the research was conducted in the absence of any commercial or financial relationships that could be construed as a potential conflict of interest.

Publisher's Note: All claims expressed in this article are solely those of the authors and do not necessarily represent those of their affiliated organizations, or those of the publisher, the editors and the reviewers. Any product that may be evaluated in this article, or claim that may be made by its manufacturer, is not guaranteed or endorsed by the publisher.

Copyright (c) $2022 \mathrm{Hu}$ and Wang. This is an open-access article distributed under the terms of the Creative Commons Attribution License (CC BY). The use, distribution or reproduction in other forums is permitted, provided the original author(s) and the copyright owner(s) are credited and that the original publication in this journal is cited, in accordance with accepted academic practice. No use, distribution or reproduction is permitted which does not comply with these terms. 